\title{
The Failure Mechanism and Stability of the End Slope of Inclined Composite Coal Seam
}

\author{
Haoran Li, ${ }^{1}$ Han Du $\mathbb{D}^{2},{ }^{2}$ Runcai Bai, ${ }^{1}$ Guangwei Liu, ${ }^{1}$ Mingyuan Zhao, ${ }^{3}$ and Rongzheng Liu ${ }^{1}$ \\ ${ }^{1}$ School of Mining, Liaoning Technical University, Fuxin 123000, Liaoning, China \\ ${ }^{2}$ Department of Hydraulic Engineering, State Key Laboratory of Hydroscience and Engineering, Tsinghua University, \\ Beijing 100084, China \\ ${ }^{3}$ Xi'an Research Institute Co. Ltd., China Coal Technology \& Engineering Group Corp, Xi'an 710054, Shaanxi, China \\ Correspondence should be addressed to Han Du; duh@mail.tsinghua.edu.cn
}

Received 23 July 2021; Revised 26 August 2021; Accepted 6 September 2021; Published 26 October 2021

Academic Editor: Sang-Bing Tsai

Copyright (c) 2021 Haoran Li et al. This is an open access article distributed under the Creative Commons Attribution License, which permits unrestricted use, distribution, and reproduction in any medium, provided the original work is properly cited.

\begin{abstract}
In view of the inclined occurrence of coal seam in Heishan open-pit coal mine, in the longitudinal exploitation process of the first mining area, the height of the slope at the west end is increasing, and the occurrence of weak interlayer in the slope is in production. The failure mechanism and stability of the end slope of the inclined composite coal seam, which is typical of the West end slope of Heishan open-pit mine, are studied by means of field investigation, theoretical analysis, limit equilibrium analysis, and numerical simulation. The factors affecting the stability of the western side slope and the potential landslide mode are analyzed. The residual thrust method and simplified Bishop method were used to study the stability of two potential landslide modes on the western slope, and the landslide mode, final slope angle, and slope morphology were determined. FLAC ${ }^{3 \mathrm{D}}$ was used to simulate the western end of the slope, reveal its landslide mechanism, and clarify the evolution law of the slope rock mass displacement. The results show that the landslide mode at the west end of the first mining area is the combined sliding mode of "cutting and bedding." With the decrease of longitudinal mining depth, the final slope angle functions from $40^{\circ}$ to $37^{\circ}$. The stress and strain are concentrated at the weak layer of the coal floor of the western side slope 13-2 and at the foot of the slope. Meanwhile, the failure also occurs inside the slope. The internal cracks connect through the weak layer of the coal floor and slide along the weak layer of the coal floor 13-2. The displacement evolution law of the slope monitoring point shows that the deformation of the slope is mainly horizontal displacement, the maximum displacement deformation is at the foot of the slope, and the degree of displacement deformation of the slope surface is obviously greater than that of the inside of the slope.
\end{abstract}

\section{Introduction}

With the increase of the number of open-pit coal mines in China and the increase of the production scale, the slope increases and steepens, and the service life increases [1-3]. Similarly, for open-pit coal mine with inclined composite coal seam, with the development of mining, the height of end-side slope keeps increasing, and the exposure number of weak interlayer also gradually increases. The coal seam occurrence of the lowest layer of coal directly affects the time and way of the establishment of the inner dump. Nearly horizontal or gently inclined coal seam, after exposing the coal floor, can be discharged as soon as possible. Inclined coal seams cannot be built up in time like near horizontal coal seams. In recent years, scholars at home and abroad have done a lot of research work on the landslide mechanism and slope stability under the influence of the weak layer in composite coal seam open-pit coal mine [4-6]. Xu et al. used the numerical analysis method to analyze the distribution characteristics of stress, strain, displacement, and deformation inside the slope rock mass and determined that the main factor controlling the slope was the weak interlayer [4]. Song et al. used the limit equilibrium method, the finite element strength reduction method, and the finite difference method to analyze the stability of the slope with multilayer weak interlayer, respectively $[5,6]$. Based on the principle of 
tensile failure, Wang et al. studied the influence of weak interlayer in the process of slope failure and concluded that, with the increase of the depth of interlayer, the surface soil of the slope is more prone to rupture [7]. Peng et al. concluded that the factors that have great influence on the stability of end slope include exposure time, end-slope shape, and slope angle [8]. Li studied the stability of the north end slope of Haerwusu open-pit coal mine. Based on the strength reduction theory and the limit equilibrium theory, the slope was gradually steepened and the optimal end slope mining angle was determined [9]. Cao et al. took the west end wall of Shengli West Second Open-pit Mine as the research object, analyzed the influence of different reserved coal pillar lengths on the end wall stability, summarized the variation law of its stability, and optimized the final slope shape [10]. However, there is still a lack of unified research method for slope stability of inclined composite coal seam open-pit mine.

In general, an open pit mine, in Xinjiang Autonomous Region, China as an example, was taken to research on the slope stability of west end slope in the first mining area. The results provide a reference for the failure mechanism and stability analysis of the end slope of inclined composite coal seam under similar conditions [11-13].

Above all, in order to eliminate the safety threat caused by landslide to the development of mining and stripping engineering in the first mining area of Heishan open-pit mine, in this paper, the stability of the western mining area of Heishan open-pit mine is studied in depth. The research results can provide guidance for the production of open-pit mine and have reference significance for slope failure mechanism and stability analysis under similar inclined composite coal.

\section{Slope Engineering Geology}

Heishan open-pit mine is about $90 \mathrm{~km}$ northwest of Tokxun County and $65 \mathrm{~km}$ north of Urumqi City. Administrative divisions are under the jurisdiction of Jackson County. The designed production capacity of Heishan open-pit mine is $10 \mathrm{Mt} / \mathrm{a}$, and the rock and soil stripping adopts the single-bucket truck intermittent process. Coal mining technology is a single bucket-trucksemifixed crushing station-belt conveyor semicontinuous technology. The truck-front loading process is used for soil disposal. Coal seams that can be mined mainly include 6 coal, 7 coal, 8 coal, 9 coal, 11 coal, 12-1 coal, 12-2 coal, and 13-2 coal.

2.1. Strata Lithology. The geotechnical body in the first mining area of Heishan open-pit mine is composed of Quaternary loose layer and Jurassic coal-bearing stratum from the top to bottom. The stratigraphic thickness, lithology, and assemblage characteristics are as follows:
(1) Quaternary Loose Layer. The Quaternary loose layers are mainly distributed in gullies, hillsides, and ridges, generally in the form of thin layers and loose layers. Only a few low-lying areas are in the form of thick layers, with an average thickness of $10.04 \mathrm{~m}$. They are located above the water level and are in the dry state. In the west of the first mining area, the Quaternary loose layer is rarely distributed and its thickness is extremely limited, so it has no influence on the stability of the west end slope. Therefore, it is not considered in the stability analysis of the west end slope.

(2) Jurassic Coal-Bearing Strata. The coal-bearing strata are mainly composed of sandstone and coal, while there are a few soft beds of mudstone and carbonaceous mudstone. The roof and floor of each coal seam are mostly developed as direct roof and floor. The lithology is medium, powdered, and fine sandstone, and only a few sections are interbedded with powdered and fine sandstone. Laoding and Laodi are the next, and the lithology is mostly medium and coarse sandstone. The pseudotop and pseudobottom are limited to local areas, and the lithology is mostly mudstone and carbonaceous mudstone.

The RQD value of rocks in the exploration area is mostly less than 25\%, some of them are between $25 \%$ and $50 \%$, and a few of them are more than $50 \%$. The rock quality grade in this area is mostly $\mathrm{V}$ grade and core-grade, and the rock quality is mostly extremely poor and poor. The rock integrity evaluation is mostly broken rock mass and poor rock integrity.

The bedrock is a set of sandstone assemblages, and the bedrock layer is well cemented sandstone. The average compressive strength of various saturated states in the openpit mine is $24.28 \mathrm{MPa}$, greater than $15 \mathrm{MPa}$. The rock strata have gentle dip angle, and the development of all kinds of structural plane is only limited to local sections.

The loose rock strata in the open-pit mine are sandy soil layers with a thickness of $0 \sim 9.20 \mathrm{~m}$ and most of them are less than $1 \mathrm{~m}$. They are thin layered and loose. According to the lithology and physical and mechanical properties of the stripped rock strata, they are classified as the first type of loose rock strata.

2.2. Geological Structure. The whole structure of the survey area is simple, the main feature is a southward dipping monoclinal structure, the stratigraphic strike is about $95^{\circ}$, the dip angle is generally $13^{\circ} \sim 25^{\circ}$, and the change of the strike dip angle is little.

In the south of the survey area, there is a thrust fault F3, a regional one, with the hanging wall of the Devonian Tianger Formation and the footer wall of the Jurassic Middle Xishanyao Formation, with a drop of more than $500 \mathrm{~m}$. The fault is east-west and about $20 \mathrm{~km}$ long. The fault dips $173^{\circ} \sim 190^{\circ}$ and dips $69^{\circ} \sim 72^{\circ}$. It has no effect on the stability of the west end. 
There is a thrust fault F4 about $7 \mathrm{~km}$ to the east of the exploration area. The fault dips $326^{\circ} \sim 328^{\circ}$ and dips $30^{\circ} \sim 45^{\circ}$. It has no effect on the stability of the west end.

There is a normal fault F5 $2.5 \mathrm{~km}$ southwest of the survey area, with a strike length of about $8 \mathrm{~km}$, a fault dip of $180^{\circ} \sim 190^{\circ}$, a dip angle of $80^{\circ} \sim 85^{\circ}$, and a drop of $100 \sim 150 \mathrm{~m}$. It has no effect on the stability of the west end.

The formation and development of the ancient fire area are the result of the neotectonic movement. Before the Pleistocene, the coal-bearing strata were exposed to the surface by the neotectonic movement, which made the 13 coal seam of the Xishanyao Formation contact with the air. After oxidation, the coal seam heated rapidly and increased temperature, resulting in spontaneous combustion. The glaciation movement of Pleistocene made the coal seam fire area extinguished and then did not spontaneously ignite. After millions of years of barbeque alteration of surrounding rock, a nearly east-west trending pyrogenic rock belt is formed. It has no effect on the stability of the west end.

2.3. Soft Interlayer. Soft intercalation refers to the thin intercalation with high content of mudstone, weak property, low mechanical strength, and easy to cause sliding between two strata. The existence of weak interlayer increases the possibility and degree of rock permeability and reduces the shear strength accordingly, which is extremely unfavorable to the stability of the slope. The formation or aggravation of rock mass cracks is caused by the weak interlayer, and the slope stability will be affected to a certain extent. Montenegro within the number of the first mining area west of the slope is a more weak carbonaceous mudstone layer, mainly including 9 coal floor, 11 coal floor, 12-2 coal floor, and 13 coal floor, the weak layer to cause adverse effect on the stability of the west to help; therefore, reasonable and accurate analysis of the weak layer of influence on the western slope stability is a focus in the study of this thesis.

2.4. Hydrogeology. Heishan open-pit mining area is located in the part of Yilin Habir dry mountain and Turpan community. It belongs to the intermountain valley at the northern foot of Tianshan Mountain. Meltwater from snow and ice in Heishan and western alpine belt is the main recharge source of regional groundwater. Alpine ice and snow meltwater from this part of the southeast flow into the Boergan and Alagou River. The floor of the river coal seam is composed of Devonian and Carboniferous strata, whose conductivity and water abundance are both weak. Groundwater becomes a perennial continuous surface flow, forming the Panjitakesu River. The flow of this river is small, and the normal flow of the river is only $0.12 \mathrm{~m}^{3} / \mathrm{s} \sim 0.21 \mathrm{~m}^{3} / \mathrm{s}$.
Meltwater of snow and ice and precipitation in mountainous areas is the main recharge source of regional groundwater. The regional precipitation is poor, and the permeability of rock strata is poor. Therefore, the hydrogeological unit of mining area belongs to the hydrogeological area with simple hydrogeological conditions and poor groundwater.

2.5. Physical and Mechanical Parameters of Rock and Soil Mass. West slope in 9 coal floor, 11 coal floor, 12 coal floor, and 13-2 coal floor are very weak carbonaceous mudstone layer; the weak layer is the main factor to control the stability of the west slope in the open-pit mine in Montenegro; the selection of the weak layer of physical and mechanical parameters of rock and soil mass also is one of the most important aspects of the slope stability analysis; through detailed analysis of Montenegro openpit mine previous geological exploration research results, combined with previous similar slope stability research and engineering geological conditions of slope mechanical parameters, we finally determine the west of physical and mechanical parameters for rock mass (as shown in Table 1), for the analysis of the rigid body limit equilibrium and FLAC ${ }^{3 \mathrm{D}}$ The numerical simulation analysis provides the database.

\section{Multilevel Limit Equilibrium Analysis of Stability of the West-End Band}

3.1. Analysis of Potential Landslide Mode in the West End. Before the stability analysis of the west-end slope of Heishan open-pit mine, the potential failure mode should be predicted first, and the stability analysis method suitable for this project should be determined based on it. According to the slope engineering geological conditions and rock mass structure control theory, the main controlling factor affecting the failure mode of the west end slope is the weak interlayer in the coal seam floor. Combined with the specific engineering geological conditions of the west end wall of Heishan open-pit mine, the potential landslide mode is analyzed as follows. (1) With the shear arc as the side, the combined failure of "cutting and bedding" is cut along the internal weak layer of the slope body $[13,14]$. The west end of the slope is an inclined stratified slope, which contains carbonaceous mudstone inside the slope. According to the parameter table of geotechnical physics and mechanics, the shear strength of carbonaceous mudstone is relatively small, and it is easy to form the weak layer after the slope is formed. (2) Arc failure is caused by sliding along the shear arc surface inside the slope. The slope load increases with the decreasing depth, and the shear strength of the rock mass decreases. Although the strength of the weak carbonate mudstone layer is weak, it does not play a major role, and 
TABle 1: Rock mess physical and mechanical indexes of west end slope.

\begin{tabular}{lccccc}
\hline Formation lithology & Severe $\left(\mathrm{kN} / \mathrm{m}^{3}\right)$ & Modulus of elasticity $(\mathrm{GPa})$ & Poisson's ratio & Cohesion $(\mathrm{KPa})$ & Internal friction angle $\left(^{\circ}\right)$ \\
\hline Coal & 14.1 & 0.80 & 0.33 & 56 & 30.5 \\
Medium sandstone & 26.1 & 4.78 & 0.29 & 88 & 38.9 \\
Fine sandstone & 26.5 & 4.98 & 0.28 & 80 & 39.1 \\
Siltstone & 26.6 & 5.48 & 0.28 & 82 & 40.5 \\
Weak layer & 21.0 & 0.20 & 0.40 & 28 & 17.1 \\
\hline
\end{tabular}

the landslide mode occurs at this time as a circular slide along a simple circular arc fracture surface.

The residual thrust method is suitable for the analysis of all sliding surface states, and the simplified Bishop method is often suitable for the calculation of circular sliding landslide. Considering that the potential landslide mode of the westend slope of the slope in Heishan open-pit mine is either the combined sliding of "cutting bed and bedding" or the circular slide, the stability of the west-end slope in the first mining area is analyzed by the residual thrust method and the simplified Bishop method.

According to the provisions on the safety factor of nonworking slope in "Code for Design of Coal Industry Open-pit Mine" (GB50197-2015), as shown in Table 2, the exposure time of the west-end slope in the first mining area of Heishan openpit mine is less than 10 years. Considering that the west-end slope contains multiple weak interlayers and bears the transportation task and combined with the economic benefits of the open-pit mine, the safety reserve factor $\mathrm{K}$ of the west-end slope in the first mining area is finally selected as 2 .

In the longitudinal mining process of the first mining area of Heishan open-pit mine, the height of the west-end wall slope is gradually increasing. In order to better evaluate and describe the shape of the west-end wall, typical profiles I VI are selected from north to south as the calculated profiles, and the locations of the calculated profiles are shown in Figure 1.

3.2. Stability Analysis of the West End. Heishan open-pit mine in the first mining area west-end slope select the profile of slope stability analysis; the combination of the slope by transportation security flat and the steps of bench height is $15 \mathrm{~m}$, slope angle is $70^{\circ}$, the steps for security guard plates are $5 \mathrm{~m}$, width to adjust the slope angle, by adjusting the transport plates and to meet the needs of the engineering, and transport flat width is not less than $20 \mathrm{~m}$. Based on the rigid body limit equilibrium theory, the residual thrust method and simplified Bishop method were used to calculate the slope stability coefficients at different sliding surface locations under different slope angles of two potential landslide modes at the west end of the first mining area. Finally, the final slope angle and slope morphology of the west end of the first mining area were determined.

3.2.1. Two-Dimensional Slope Stability Analysis System. The two-dimensional slope stability analysis system is developed on the basis of AutoCAD platform, VBA
TABLE 2: Safety reserve coefficient selection.

\begin{tabular}{lcc}
\hline Slope type & Length of service $(\mathrm{A})$ & Safety factor, $F_{s}$ \\
\hline & The $<10$ & $1.1 \sim 1.2$ \\
Nonworking slope & $10 \sim 20$ & $1.2 \sim 1.3$ \\
& $>20$ & $1.3 \sim 1.5$ \\
\hline
\end{tabular}

language programming, man-machine interactive computer-aided design technology, and the Bishop method and residual thrust method in the rigid body limit equilibrium theory. Through this system, the most dangerous slippery surface of the slope can be easily searched out and the corresponding stability coefficient can be calculated. The architecture of the two-dimensional slope stability analysis system is shown in Figure 2.

(1) Create Engineering Geology Data Table. The engineering geology data table is mainly used to store the physical and mechanical indexes of rock mass so that these indexes can be used to calculate the stability automatically when the system is running. The table of engineering geological data is shown in Table 3.

(1) Establish the Mathematical Model of the Slope Stability Evaluation Method.

(1) The mathematical model of the Bishop method: Bishop's method is a method widely used in the engineering field of the slide-splitting method. It is assumed that the sliding surface and sliding soil are rigid bodies without deformation, and considering the effects of both sides of the soil strip, the soil above the slide-splitting surface is divided into several vertical soil strips. The formula of safety factor is as follows:

$$
F_{s}=\frac{\sum 1 / M_{i}\left\{C_{i} B_{i}+\left[W_{i}+\left(X_{i}-X_{i+1}\right)\right] \tan \varphi_{i}\right\}}{\sum W_{i} \sin \alpha_{i}}
$$

where $X_{i}$ and $X_{i+1}$ are unknown. In order to solve the problem, Bishop also assumes that the forces between tangential strips are omitted, and the formula can be simplified as

$$
\begin{aligned}
F_{s} & =\frac{\sum 1 / M_{i}\left\{C_{i} B_{i}+W_{i} \tan \varphi_{i}\right\}}{\sum W_{i} \sin \alpha_{i}}, \\
M_{i} & =\frac{\cos \alpha_{i}+\tan \phi_{i} \sin \alpha_{i}}{F_{s}},
\end{aligned}
$$




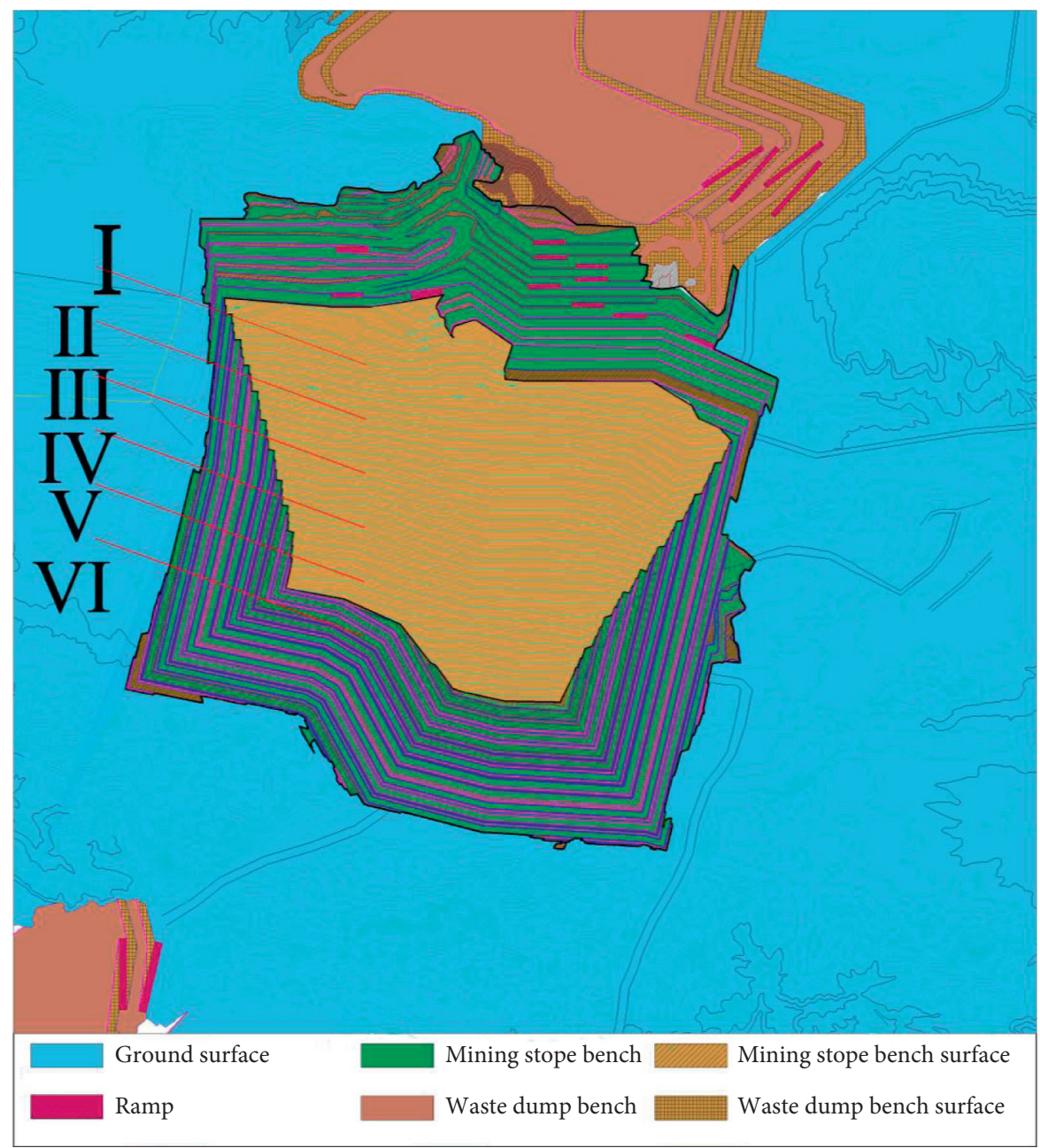

Figure 1: Profile location plan.

where $C$ is cohesive force of soil, $\varphi$ is the angle of internal friction of soil. $W_{i}$ is weight of the $i$ sliver, $B_{i}$ is width of the $i$ soil strip, and $\alpha_{i}$ is the dip angle of the sliding surface of the $i$ block.

Since there is also $F_{s}$ in equation (2), the solution must be solved by the iterative method. First, suppose the value of FS, and obtain the value of MI according to equation (3). Then, substitute MI into equation (2) to obtain the value of FS. If this value is not consistent with the assumed value, then recalculate MI with this value to obtain the new value of FS. So, repeating iteration, until the error between the calculated value and the assumed value is less than $0.5 \%$, the slope stability safety factor can be calculated.

The stability coefficient obtained by the Bishop method is generally larger than that obtained by the Swedish circular arc method. The calculation is simple but requires iterative solution and the accuracy is high. The results differ little from that obtained by the strict method. Moreover, due to the development of computer technology, technology is more mature, in a large extent, has been widely used. The calculation flow of the Bishop method is shown in Figure 3.

(2) Mathematical model of the residual thrust method: residual thrust method, also known as the unbalanced thrust transfer method, is a widely used segment method. The residual thrust method assumes that the direction of the market interatomic forces, its important premise is to assume that the current market at the interface of a body under the direction of thrust parallel to the current bar at the bottom of the sliding surface, and then according to the parallel to the bottom of sliding surface and sliding surface is perpendicular to the bottom two direction of resultant force is zero and the front bar residual thrust to zero for iteration. After solving the whole sliding body, block I is taken, and it is assumed that the direction of the force transmitted by block $i-1$ is parallel to the bottom sliding surface of block $i-1$, while the direction of the force transmitted by block I to block I +1 is parallel to the bottom sliding surface of block I.

The equilibrium expression is 


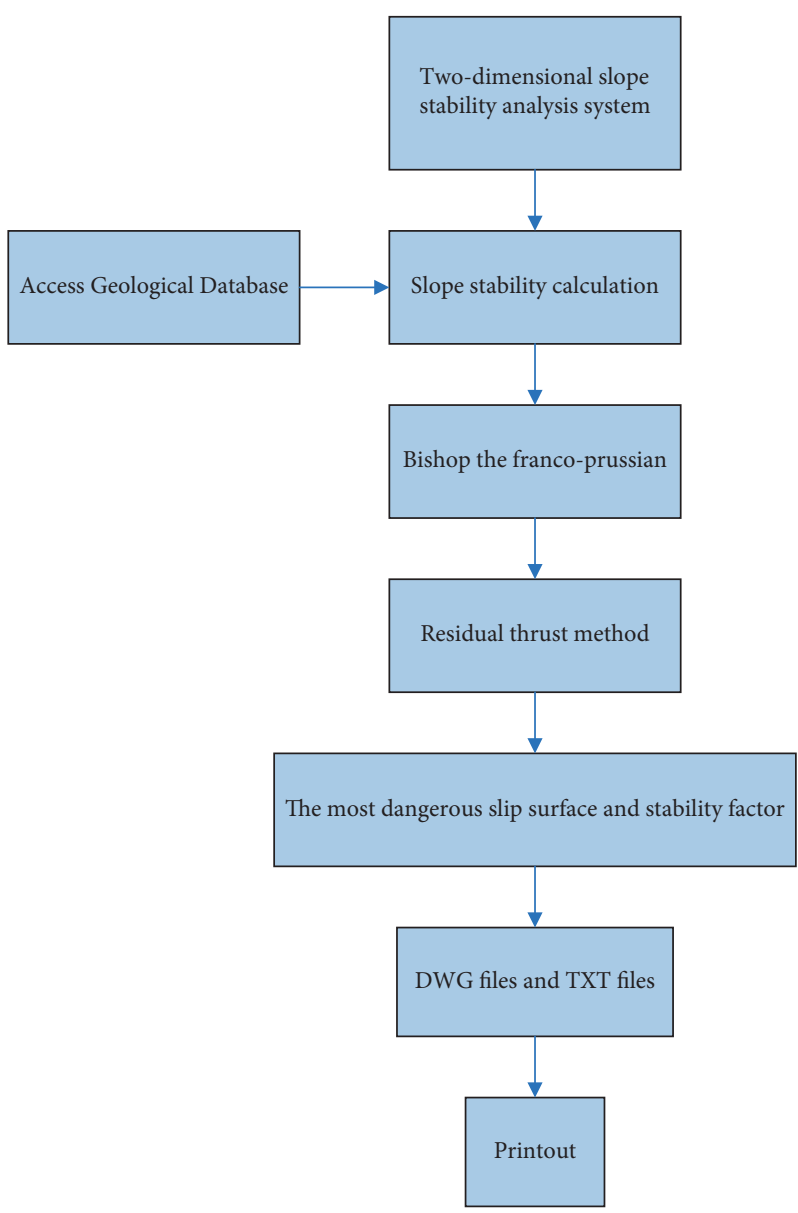

FIgURE 2: Architecture of the two-dimensional slope stability analysis system.

TABLE 3: Engineering geological data table.

\begin{tabular}{lccccc}
\hline Serial number & Lithology & Internal friction angle $(\varphi)$ & Cohesion $(c)$ & Moisture content $(d)$ & Bulk density $(v)$ \\
\hline 1 & Coal & 28 & 0.113 & 0 & 19.6 \\
\hline
\end{tabular}

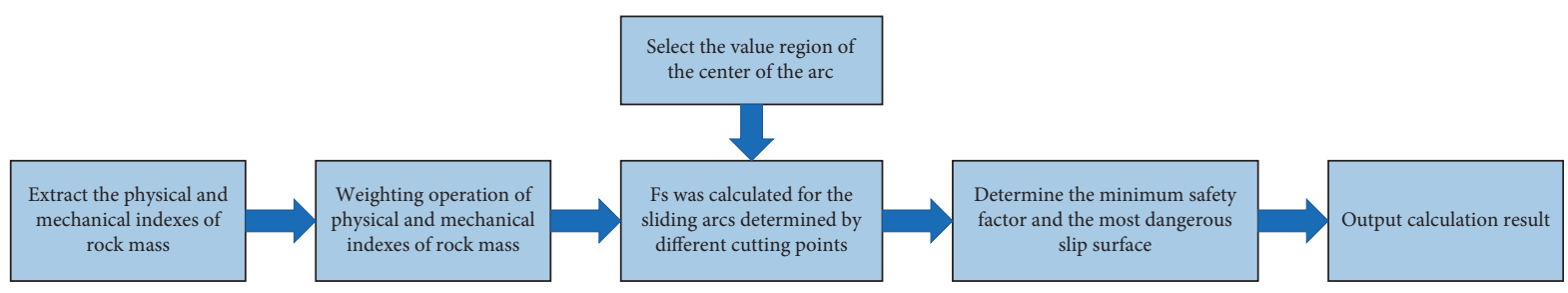

FIGURE 3: Calculation block diagram of the Bishop method.

$$
\begin{aligned}
& E_{i}=\frac{W_{i} \sin \alpha_{i}-\left(W_{i} \cos \alpha_{i} \tan \varphi_{i}+C_{i} L_{i}\right)}{K+\psi_{i} E_{i-1}}, \\
& \psi_{i}=\frac{\cos \left(\alpha_{i-1}-\alpha_{i}\right)-\tan \varphi_{i} \sin \left(\alpha_{i-1}-\alpha_{i}\right)}{K},
\end{aligned}
$$

where $\psi_{i}$ is the thrust transfer coefficient of the $i$ block, $E_{i}$ is residual thrust of the $i$ block, $W_{i}$ is weight of the $i$ block, $\varphi_{i}$ is the dip angle of the slip surface of the $i$ block, $\alpha_{i}$ is the friction angle of the sliding surface of the $i$ block, $C_{i}$ refers to the cohesive force of the sliding surface of the $i$ block, $L_{i}$ is the length of the bottom surface of the $i$ block, and $K$ is the stability coefficient. When calculating, first assume a FS value and calculate $E_{i}$ one by one from the top to bottom. When $E_{n}>0$ appears, it indicates that the value is high. When $E_{n}<0$ 
occurs, it indicates that it is low and should be adjusted appropriately until $E_{n}=0$ is met, and the value of $F_{s}$ is the desired value.

The advantage of the residual thrust method is that the landslide thrust of the sliding surface of any shape under complex loads can be obtained by means of the analysis of the landslide structural characteristics and the calculation of residual thrust, and the calculation is simple. The process of residual thrust method is shown in Figure 4.

(3) Calculation of stability coefficient: in the calculation of the profile, first run the Bishop method to search the dangerous slip surface and the corresponding stability coefficient calculation. Then, the dangerous slip surface searched by the Bishop method was used as the initial slip surface, and the residual thrust method was used to search the most dangerous slip surface. At the same time, the corresponding stability coefficient and the thrust value between each strip were calculated.

\subsubsection{Analysis Results of Sliding Stability of the Combination} of the West-End Wall. Two-dimensional limit equilibrium analysis method is the most commonly used and simplest method for slope stability analysis in open-pit coal mines [15-17].

3.2.3. Analysis Results of Sliding Stability of the Circular Arc on the West End. Figures 5-7 and Figure 8 are drawn according to the stability calculation results of each section at the west end. By comparing Figure 6 and Figure 8, it can be seen that the slope stability coefficient under circular sliding is greater than the slide stability coefficient of slice layer under bedding "combination" under the same slope angle, indicating that the potential landslide model of the western slope is "bedding"-layered combined sliding. When the potential landslide mode of the west end is "cutting and bedding" sliding, it meets both the safety factor requirements and the actual engineering requirements. The stable slope angles of sections I VI are $40^{\circ}, 39^{\circ}, 38^{\circ}, 38^{\circ}$, and $37^{\circ}$, respectively. The width of the corresponding transport flat plate is $20 \mathrm{~m}, 20.5 \mathrm{~m}, 22.4 \mathrm{~m}, 22.3 \mathrm{~m}, 23.9 \mathrm{~m}$, and $25 \mathrm{~m}$, that is, the final slope angle of the west-end slope stability decreases from $40^{\circ}$ to $37^{\circ}$ with the decreasing depth of the longitudinal mining in the first mining area. Table 4 shows the final slope angle and slope morphology parameters of the west end, and the final slope morphology plan of the west end is shown in Figure 9.

\section{Based on FLAC ${ }^{3 D}$ Numerical Simulation on the Mechanism of Landslide at the West End}

FLAC $^{3 \mathrm{D}}$ is $3 \mathrm{D}$ display finite difference software developed by Itasca for numerical simulation analysis. At present, the analysis software $\mathrm{FLAC}^{3 \mathrm{D}}$ numerical simulation is widely used in the field of geotechnical engineering; its polyhedron cell model, a variety of materials, after damage can produce corresponding deformation mobile; at the same time, it uses a unique "explicit Lagrange algorithm" and "mixed discrete partition" technology; the technology makes it different from other numerical simulation software. It can accurately describe the shear failure and plastic penetration state and can use a small memory space to solve a large range of twodimensional or three-dimensional geotechnical engineering problems and large deformation analysis. FLAC ${ }^{3 \mathrm{D}}$ numerical simulation software is one of the best tools to solve geotechnical engineering problems because it can simulate mechanical behavior well and shows great advantages in solving geotechnical engineering problems. In FLAC ${ }^{3 \mathrm{D}}$, the volume modulus $K$ and shear modulus $G$ were used as simulation calculation parameters. The relation between the elastic modulus $E$ and Poisson's ratio $\mu$ is

$$
\begin{aligned}
& K=\frac{E}{3(1-2 \mu)}, \\
& G=\frac{E}{2(1+\mu)} .
\end{aligned}
$$

In FLAC ${ }^{3 \mathrm{D}}$, there are a variety of material models, and each model has its corresponding constitutive characteristics. The Mohr-Coulomb elastoplastic model is the most commonly used constitutive model, in which the cohesion force and internal friction angle are important parameters of Mohr-Coulomb model $c \phi$. Therefore, this paper uses the Mohr-Coulomb constitutive model to conduct numerical simulation analysis on the stability of the west-end slope of Heishan open-pit mine.

4.1. Establishment of the West-End Slope Model. The core method of model establishment is ANSYS to FLAC ${ }^{3 \mathrm{D}}$. The whole slope model is established in ANSYS software, and the nodes and units of the model are divided with certain precision. The intermediate process is to import ANSYS model data into FLAC $^{3 \mathrm{D}}$ using the two-way conversion software ${ }^{3 \mathrm{D}}$ File, and finally, use FLAC ${ }^{3 \mathrm{D}}$. The simulation was carried out. The numerical model when the slope angles of profile I VI are $40^{\circ}, 39^{\circ}, 39^{\circ}, 38^{\circ}, 38^{\circ}$, and $37^{\circ}$, respectively, is shown in Figure 10.

4.2. Analysis of Numerical Simulation Results of the West-End Slope. Figure 11 shows the displacement distribution and vector diagram. The simulation results of profiles I-VI show that the displacement direction of the slope is downward sliding from the top to the foot of the slope along the edge of the slope and then out at the foot of the slope. From the top to the bottom of the slope, the displacement of the slope increases, and the displacement at the foot of the slope reaches the maximum. The mechanical cause of the displacement is "traction" failure.

Figure 12 is the shear strain increment diagram. The simulation results of profiles I-VI show that the shear strain increment is obvious at the foot of the edge slope and the weak layer (the weak layer of 13-2 coal floor), where the region first enters the plastic state. At the same time, the shear strain occurs inside the slope due to its own gravity, 


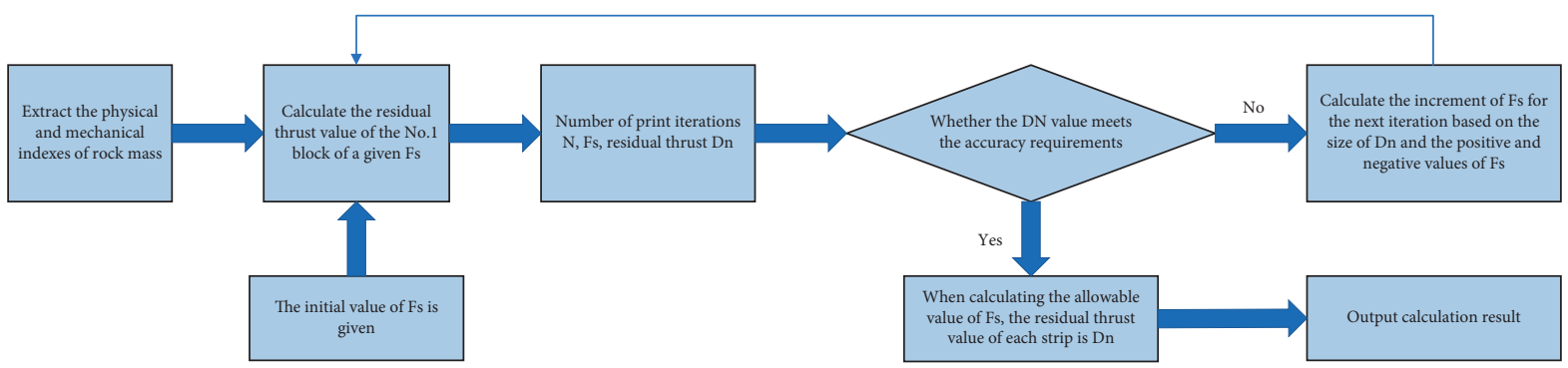

FIGURE 4: Calculation block diagram of the residual thrust method.

Elevation (m)

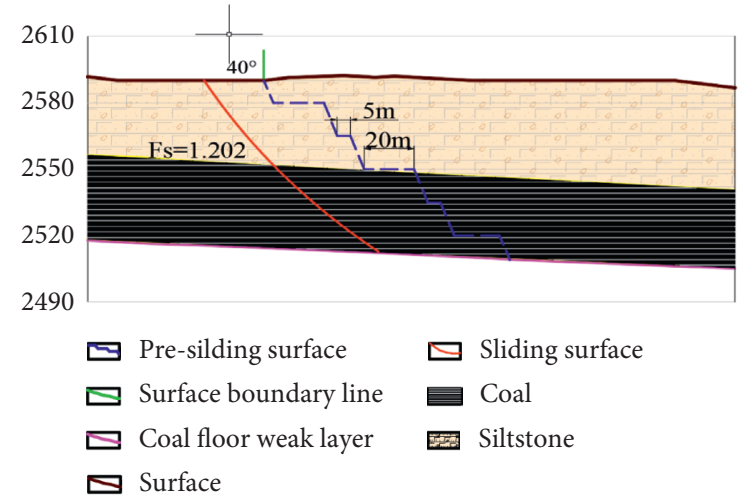

(a)

Elevation $(\mathrm{m})$

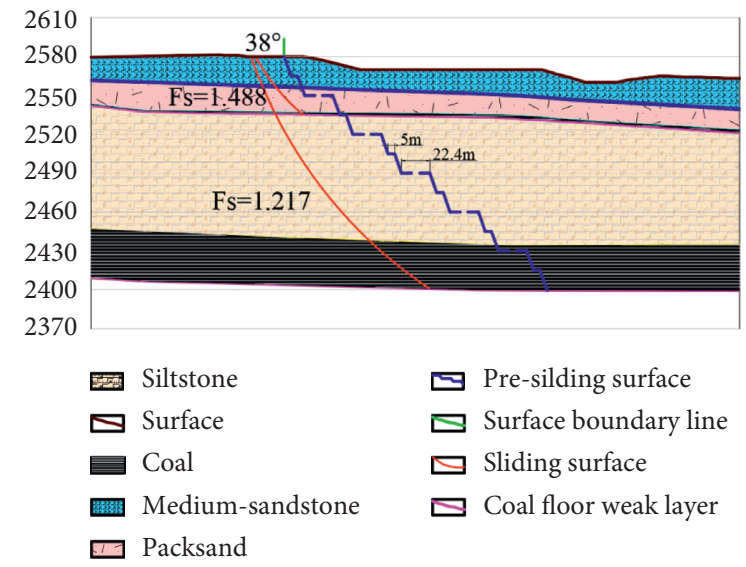

(c)

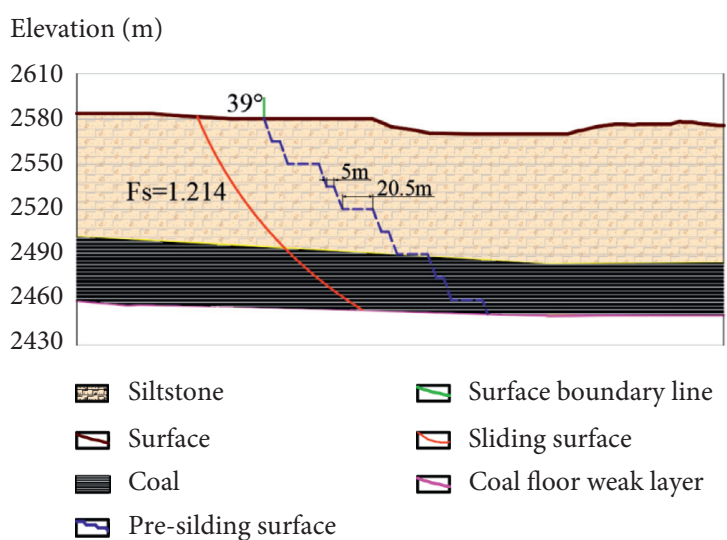

(b)

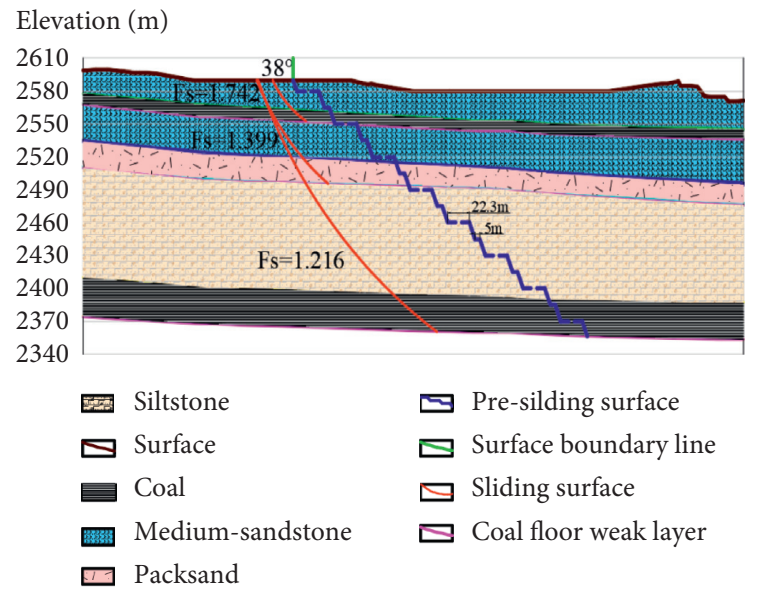

(d)

FIgURE 5: Continued. 


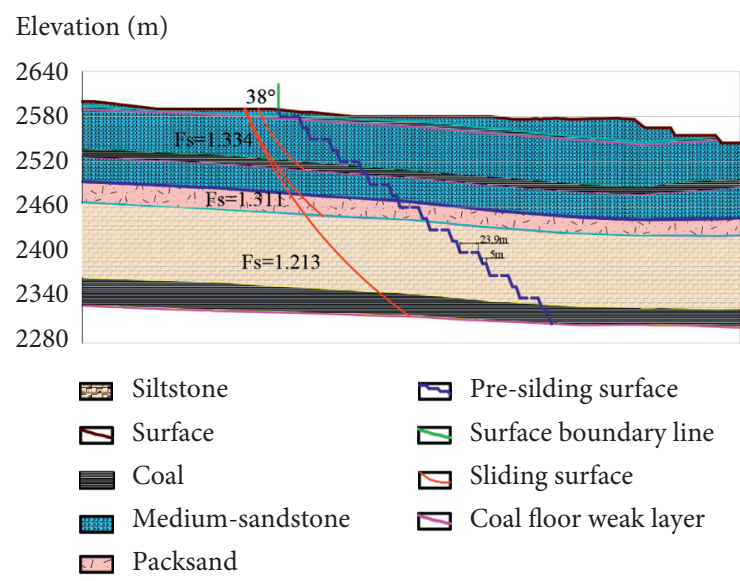

(e)

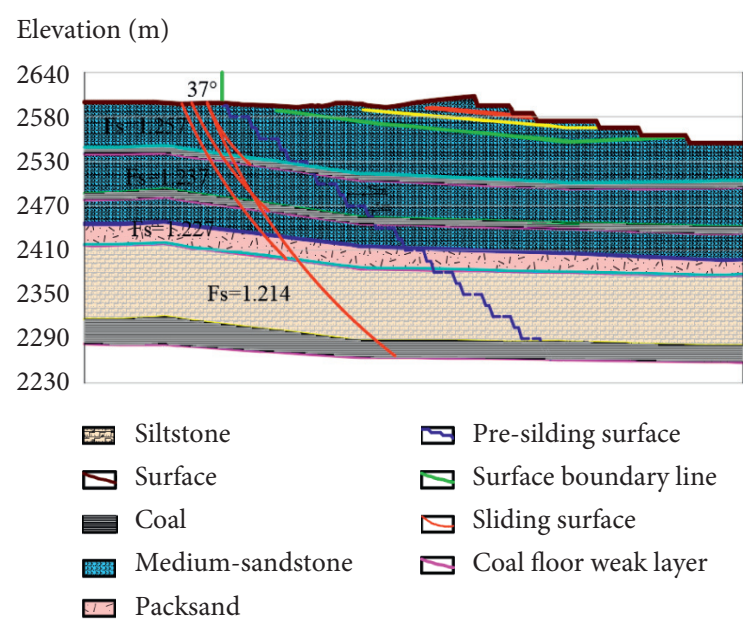

(f)

Figure 5: Stability coefficient of west-end slope under different slope angles. (a) The slope angle in profile I is $40^{\circ}$. (b) The slope angle in profile I is $39^{\circ}$. (c) The slope angle in profile I is $38^{\circ}$. (d) The slope angle in profile I is $38^{\circ}$. (e) The slope angle in profile I is $38^{\circ}$. (f) The slope angle in profile $\mathrm{I}$ is $37^{\circ}$.

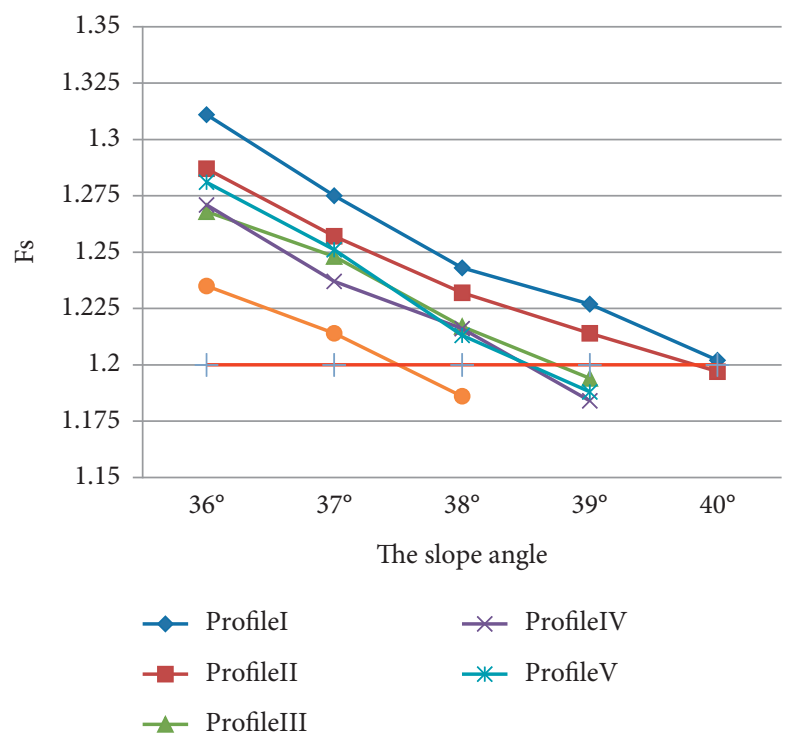

FIGURE 6: The stability coefficient of each profile at the west end is the slope angle change diagram.

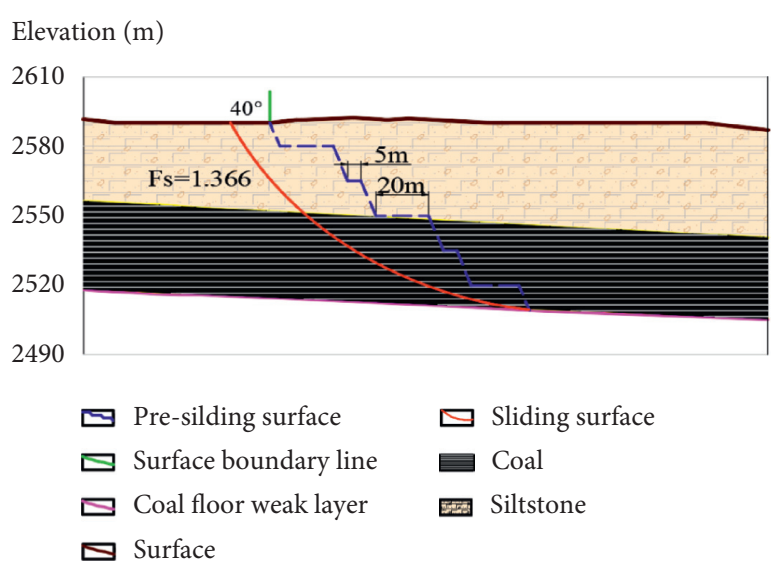

(a)

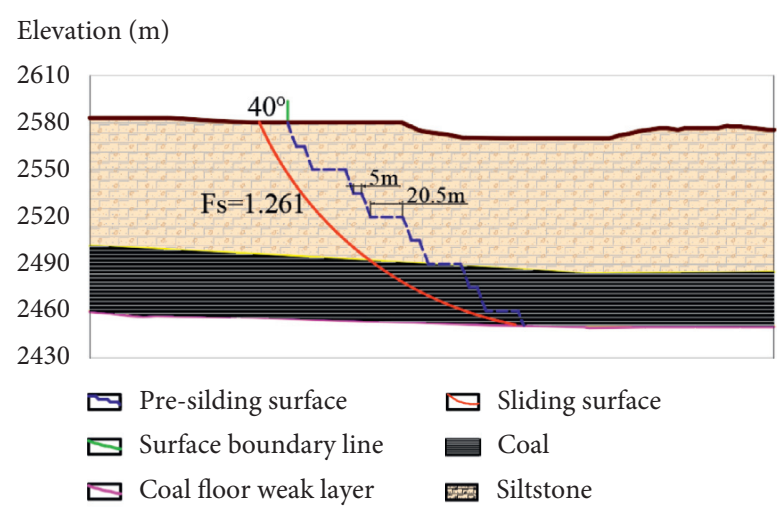

$\square$ Surface

Figure 7: Continued. 


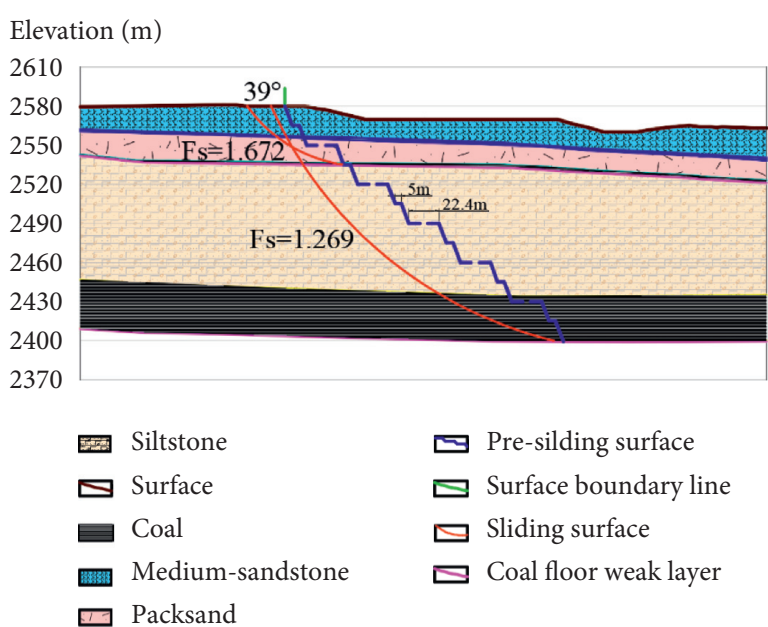

(c)

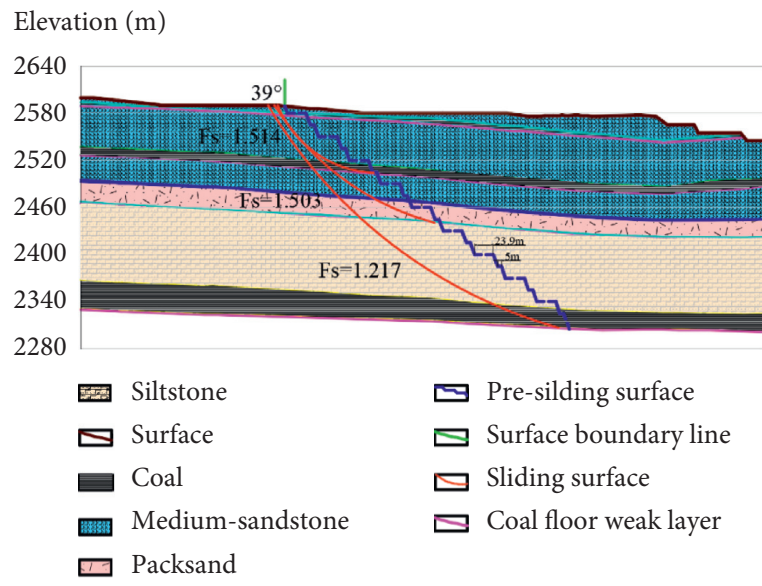

(e)
Elevation (m)

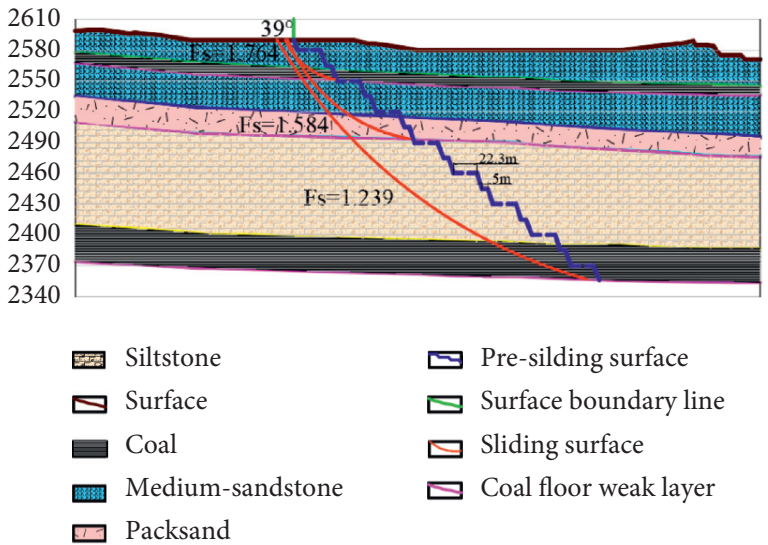

(d)

Elevation $(\mathrm{m})$

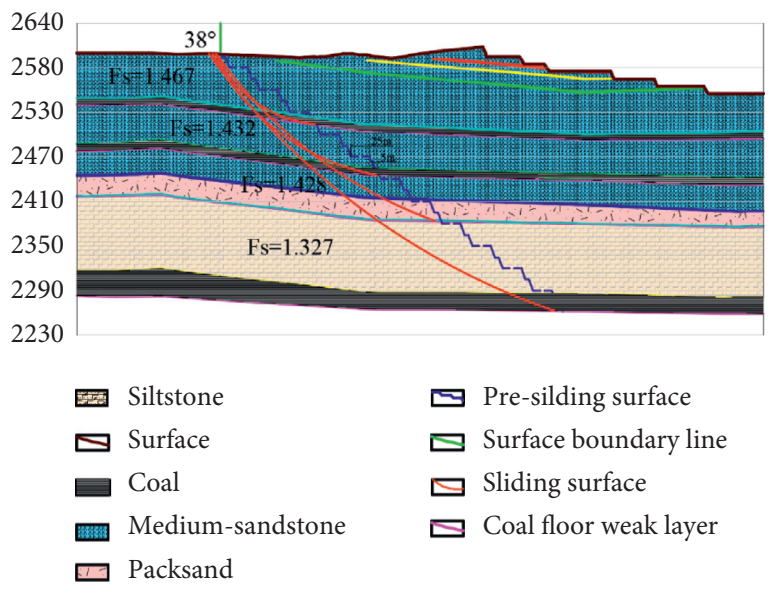

(f)

Figure 7: Stability coefficient of west-end slope under different slope angles. (a) The slope angle in profile I is $40^{\circ}$. (b) The slope angle in profile I is $40^{\circ}$. (c) The slope angle in profile I is $39^{\circ}$. (d) The slope angle in profile I is $39^{\circ}$. (e) The slope angle in profile I is $39^{\circ}$. (f) The slope angle in profile $\mathrm{I}$ is $38^{\circ}$.

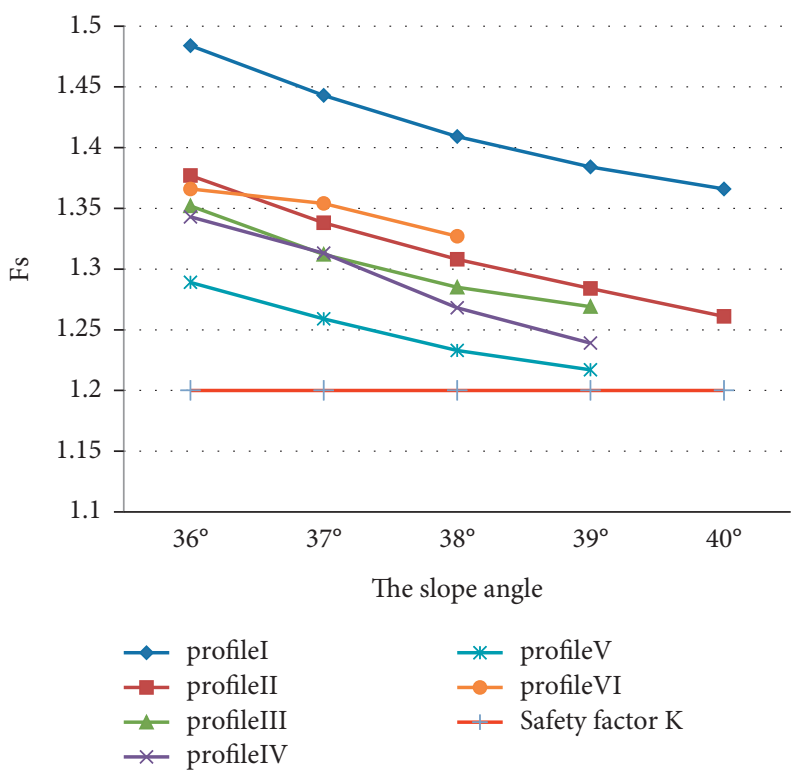

Figure 8: Stability coefficient of west-end slope under different slope angles. 
TABLE 4: Slope parameters of every profile of west-end slope.

\begin{tabular}{|c|c|c|c|c|c|c|}
\hline & Profile I & Profile II & Profile III & Profile IV & Profile V & Profile VI \\
\hline Slope angle $\left({ }^{\circ}\right)$ & 40 & 39 & 38 & 38 & 38 & 37 \\
\hline Transportation flat plate $(\mathrm{m})$ & 20 & 20.5 & 22.4 & 22.3 & 23.9 & 25 \\
\hline Slope height (m) & 80.79 & 129.35 & 180.78 & 233.81 & 283.65 & 346.06 \\
\hline
\end{tabular}

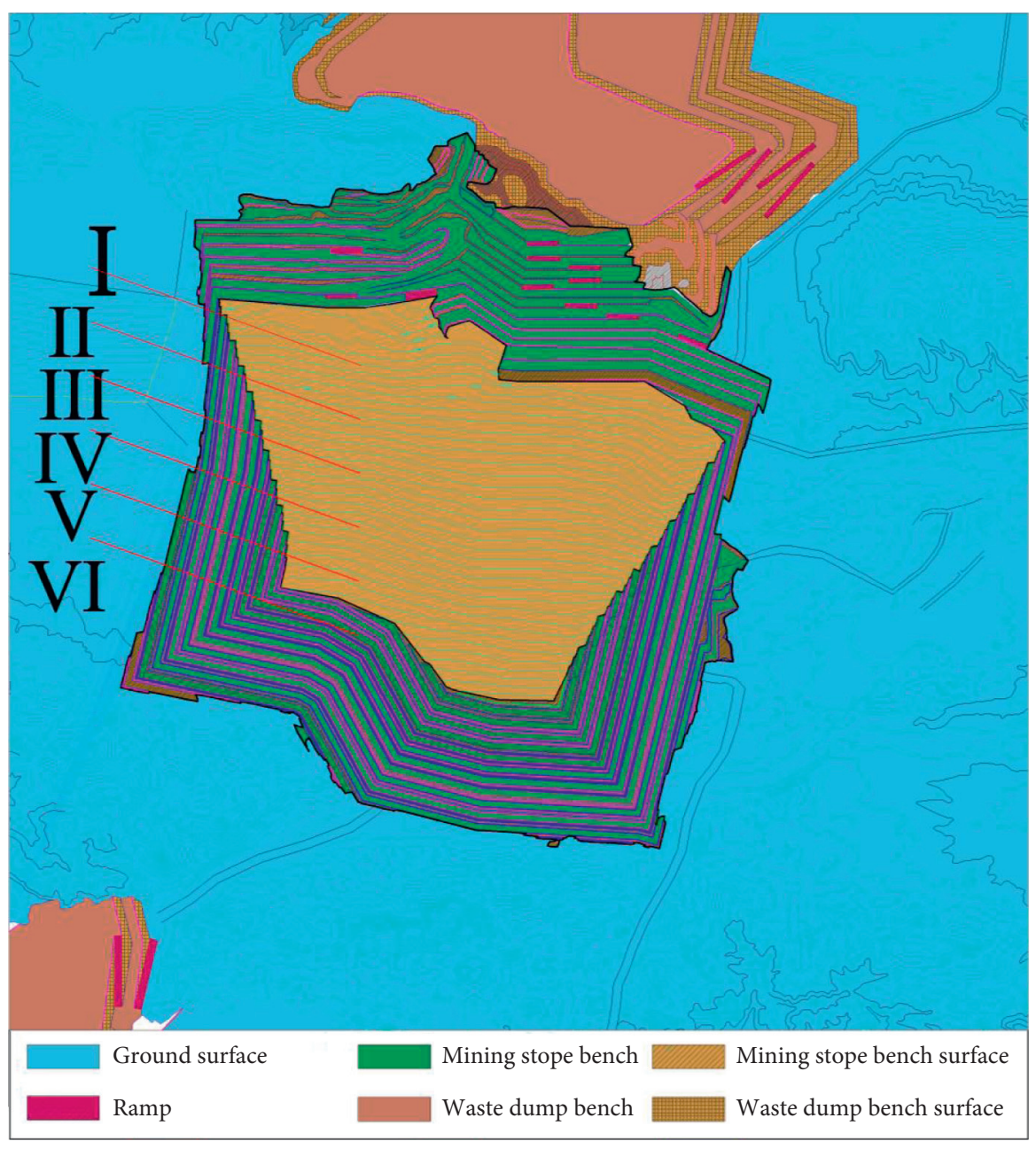

Figure 9: The final slope of west-end slope.

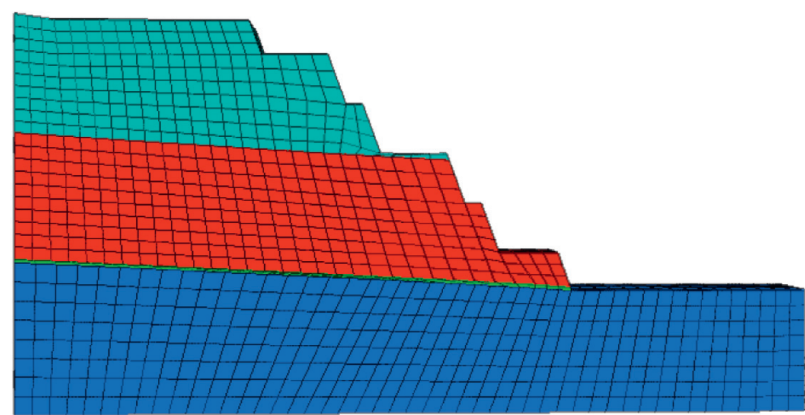

(a)

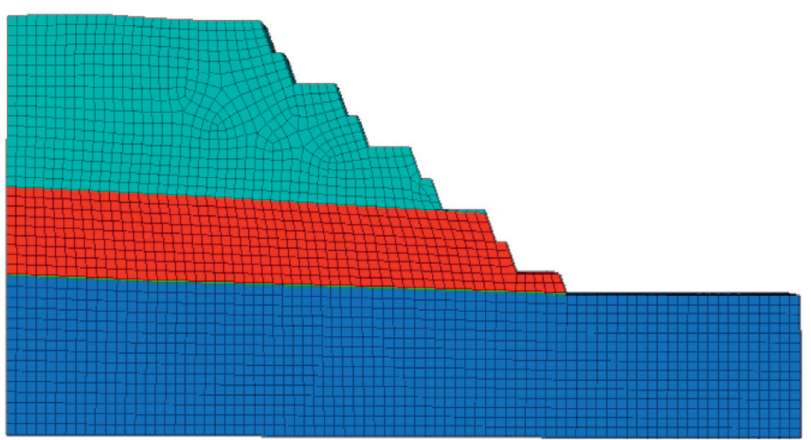

(b)

FIgURE 10: Continued. 


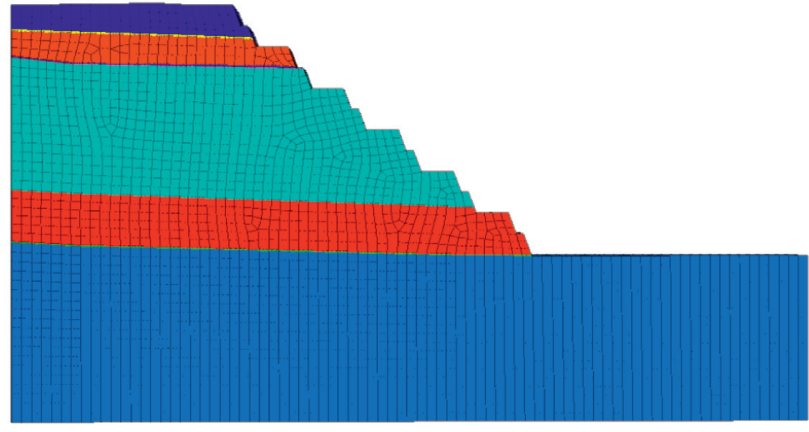

(c)

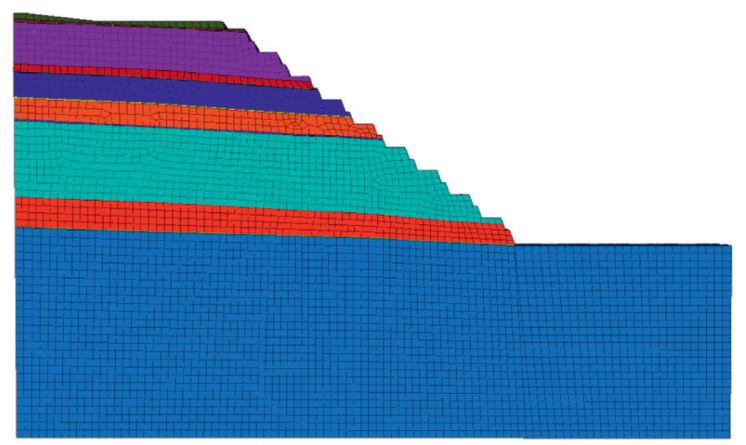

(e)

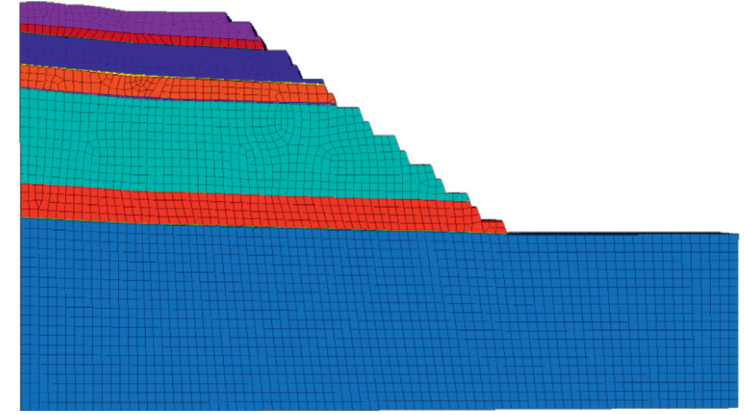

(d)

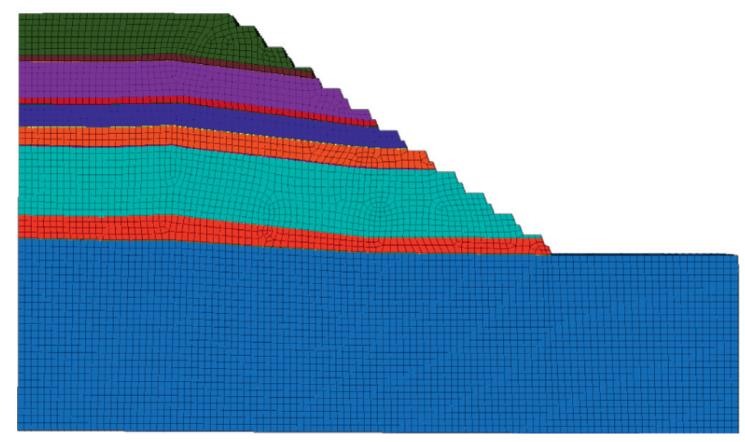

(f)

Figure 10: Numerical simulation models of the west-end slope. (a) Numerical model of profile I. (b) Numerical model of profile II. (c) Numerical model of profile III. (d) Numerical model of profile IV. (e) Numerical model of profile V. (f) Numerical model of profile VI.

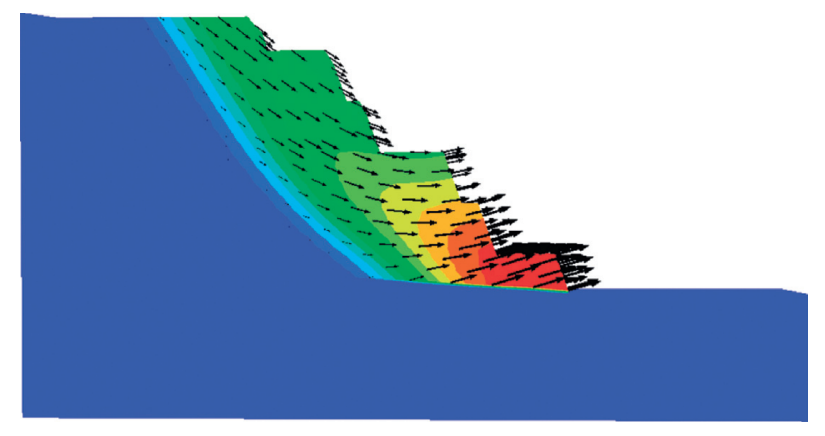

(a)

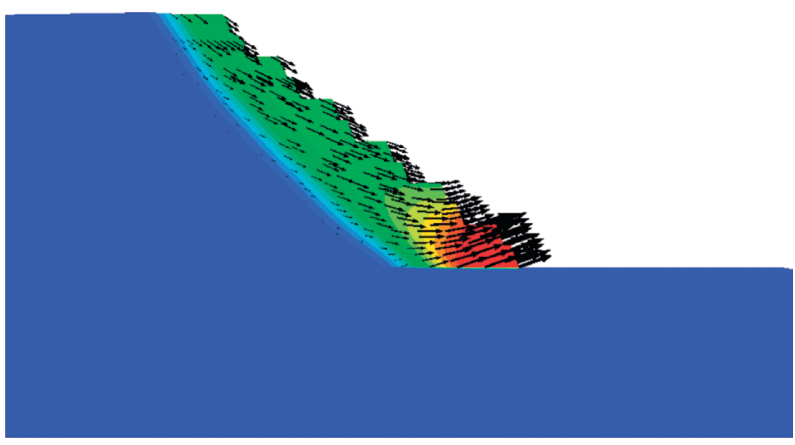

(c)

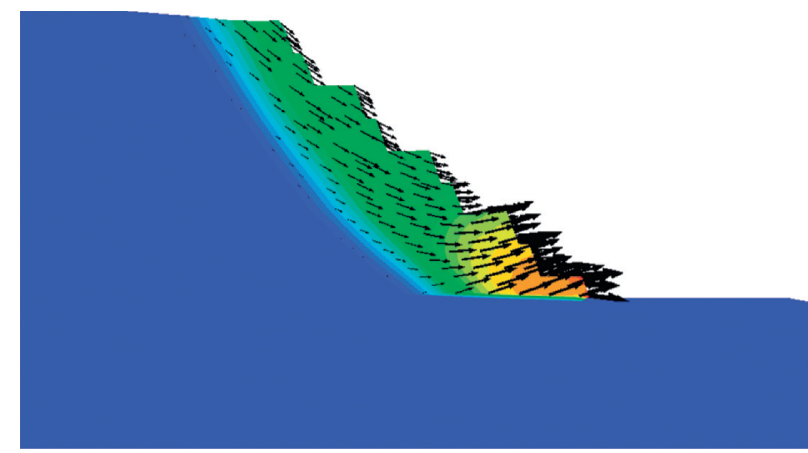

(b)

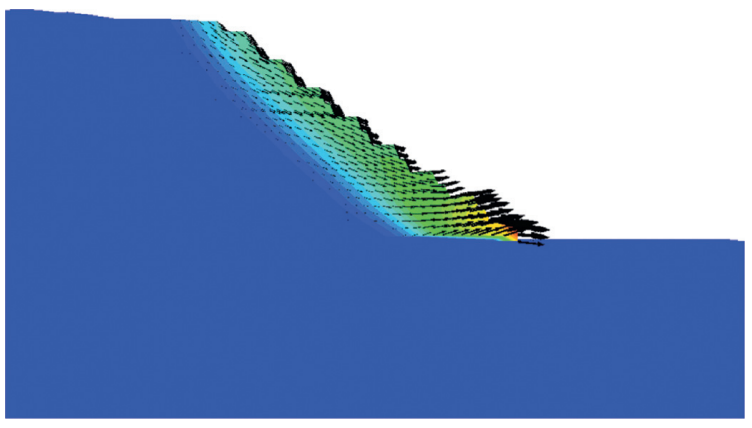

(d)

Figure 11: Continued. 


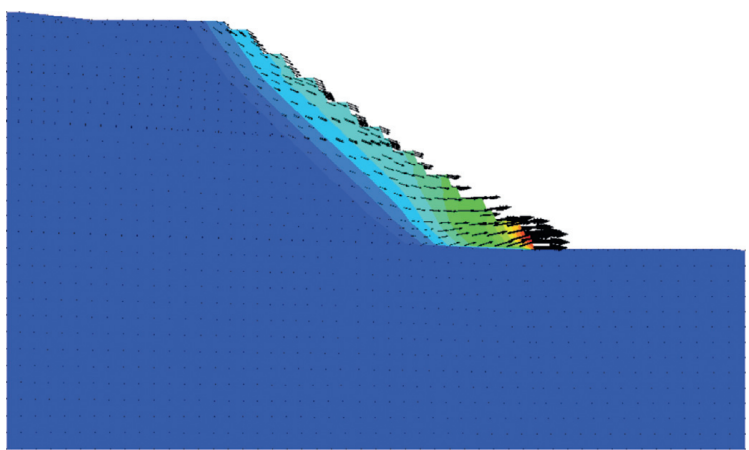

(e)

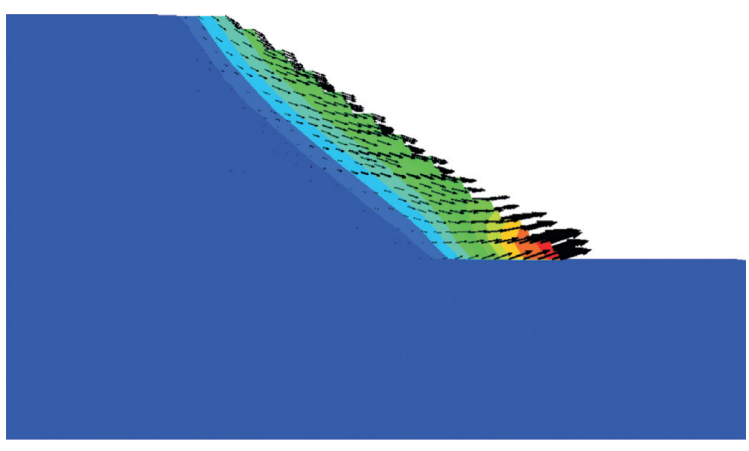

(f)

FIGURE 11: Displacement distribution and velocity vector diagram of profiles I-VI. (a) Displacement distribution and velocity vector of profile I. (b) Displacement distribution and velocity vector of profile II. (c) Displacement distribution and velocity vector of profile III. (d) Displacement distribution and velocity vector of profile IV. (e) Displacement distribution and velocity vector diagram of profile V. (f) Displacement distribution and velocity vector diagram of profile VI.

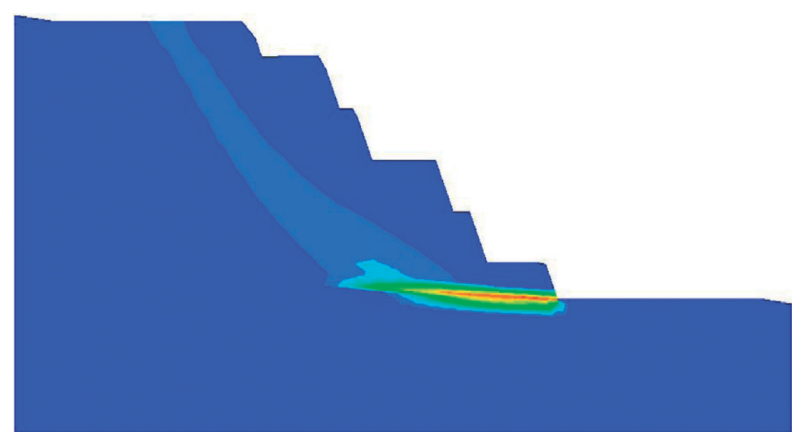

(a)

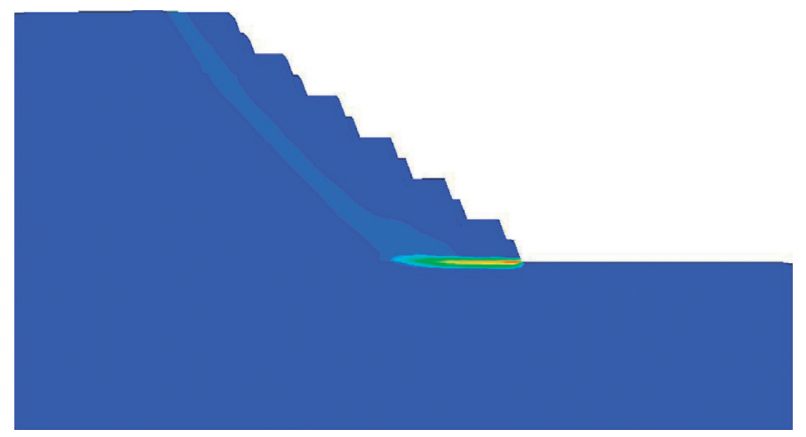

(c)

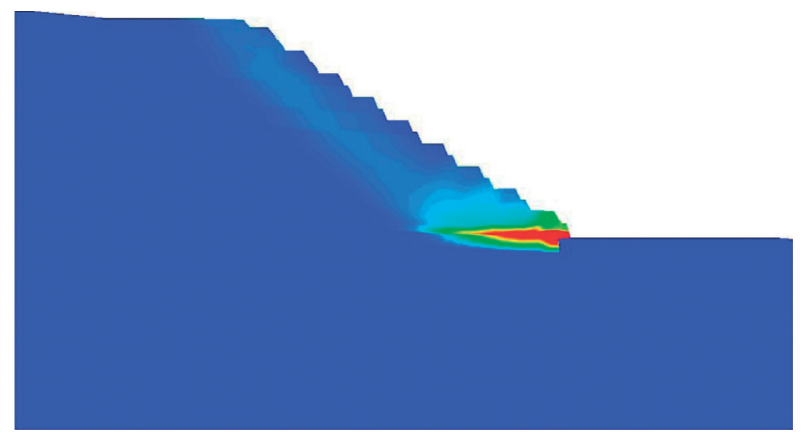

(e)

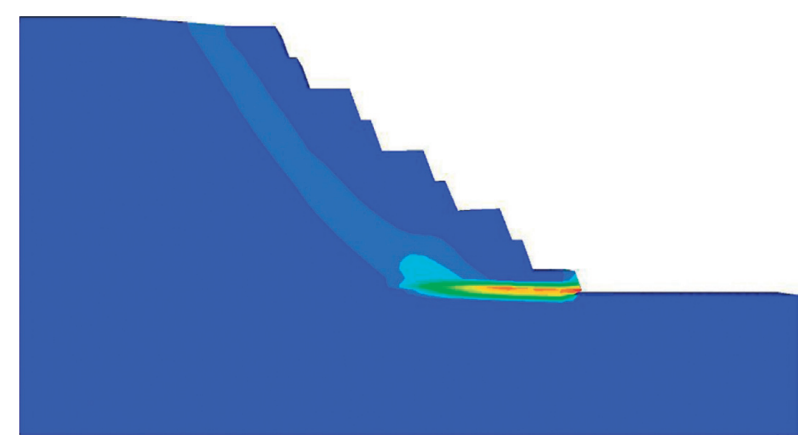

(b)

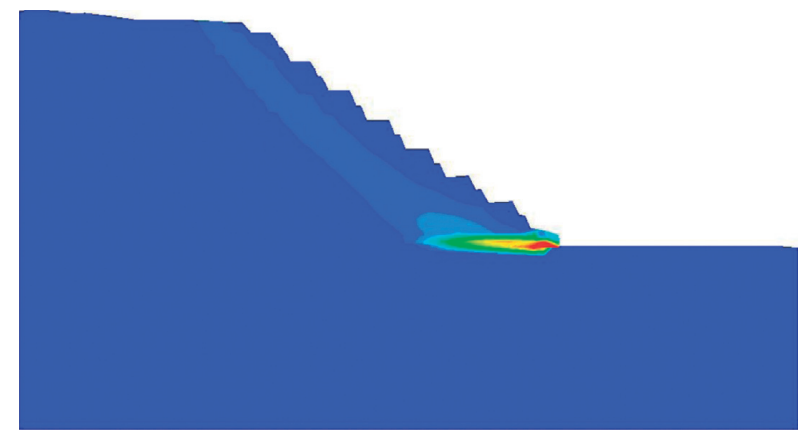

(d)

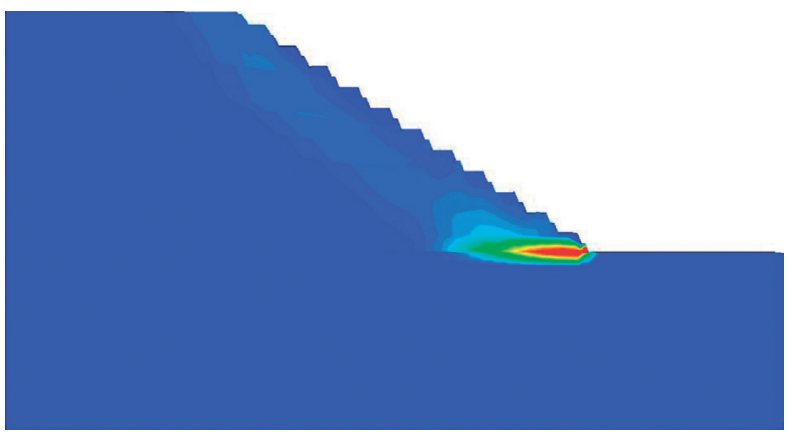

(f)

FIGURE 12: Searing strain increment diagram of profiles I-VI. (a) Shear strain increment diagram of profile I. (b) Shear strain increment diagram of profile II. (c) Shear strain increment diagram of profile III. (d) Shear strain increment diagram of profile IV. (e) Shear strain increment diagram of profile V. (f) Shear strain increment diagram of profile VI. 


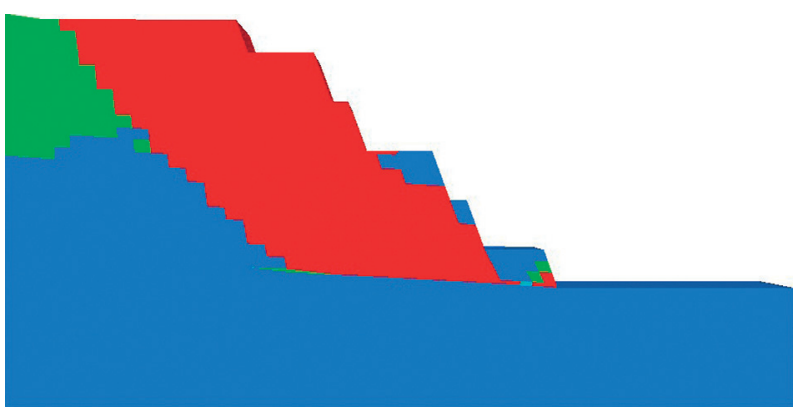

(a)

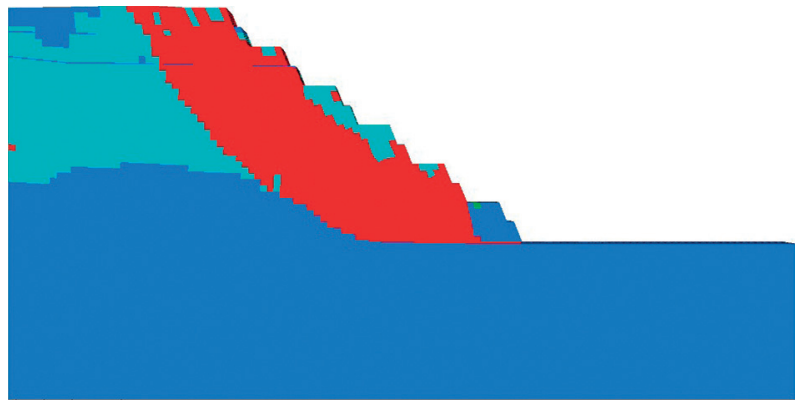

(c)

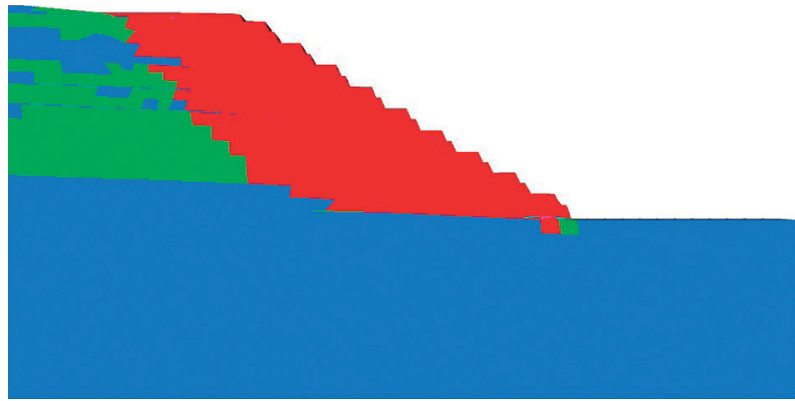

(e)

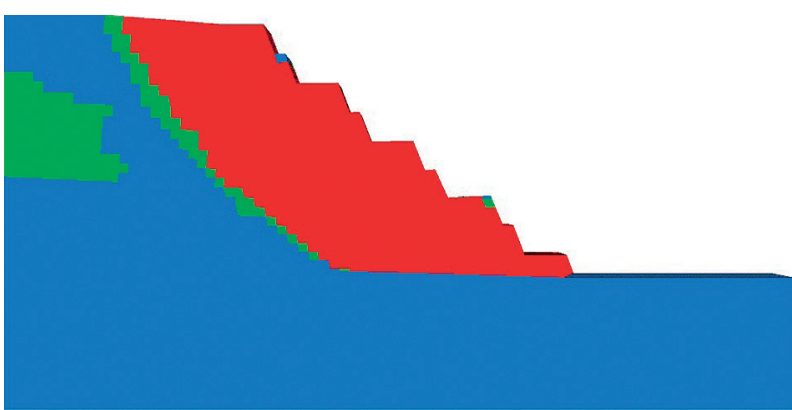

(b)

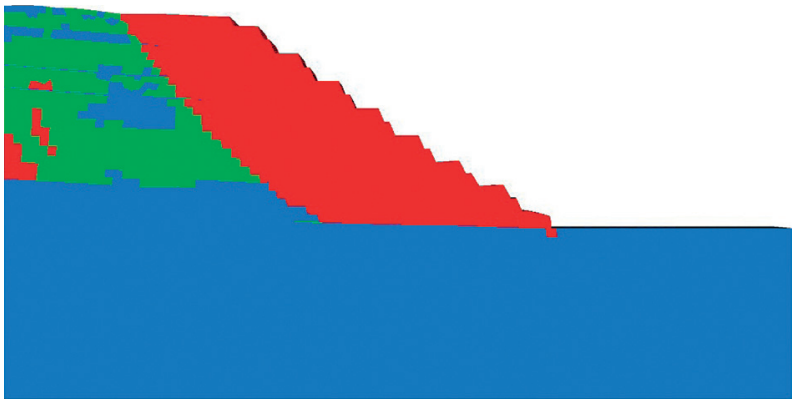

(d)

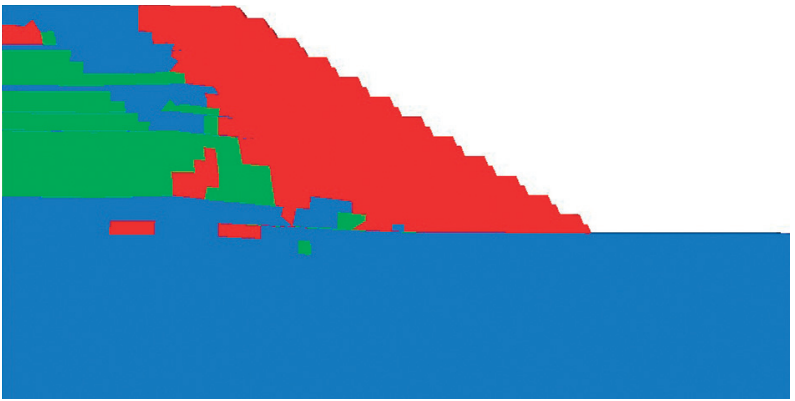

(f)

FIGURE 13: Plastic differentiation layout of profiles I-VI. (a) Plastic zone distribution in profile I. (b) Plastic zone distribution in profile II. (c) Distribution of the plastic zone in profile III. (d) Distribution of the plastic zone in profile IV. (e) Plastic zone distribution of profile V. (f) Plastic zone distribution of profile VI.

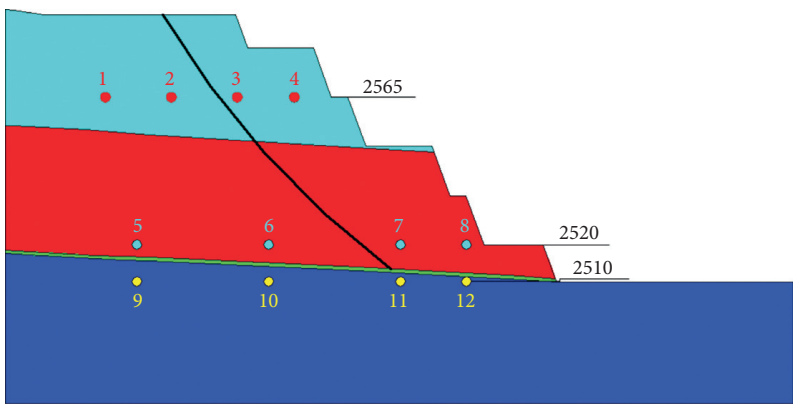

(a)

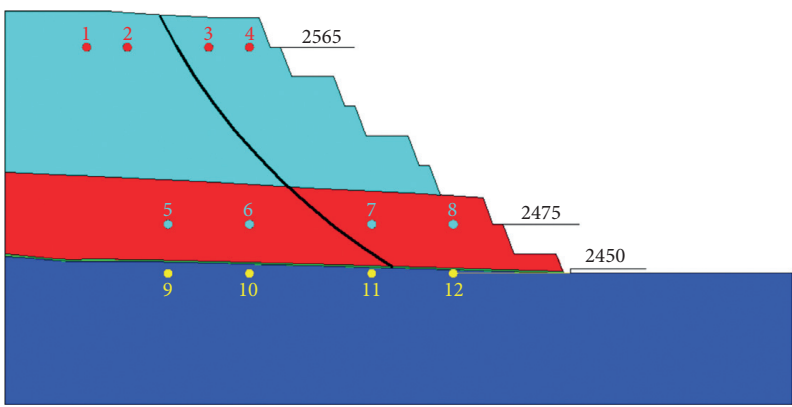

(b)

FIGURE 14: Continued. 


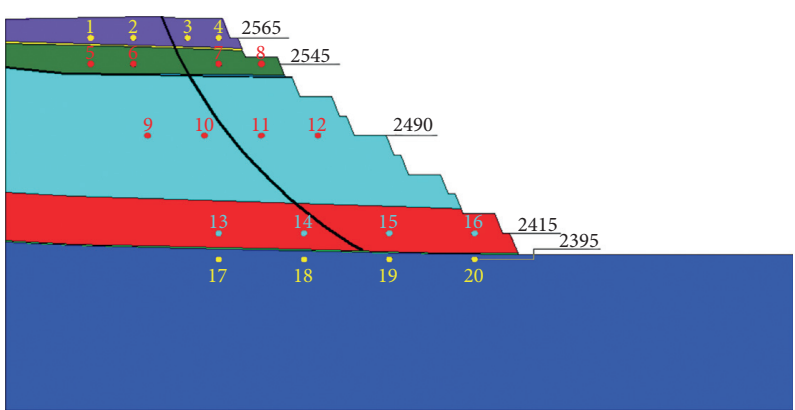

(c)

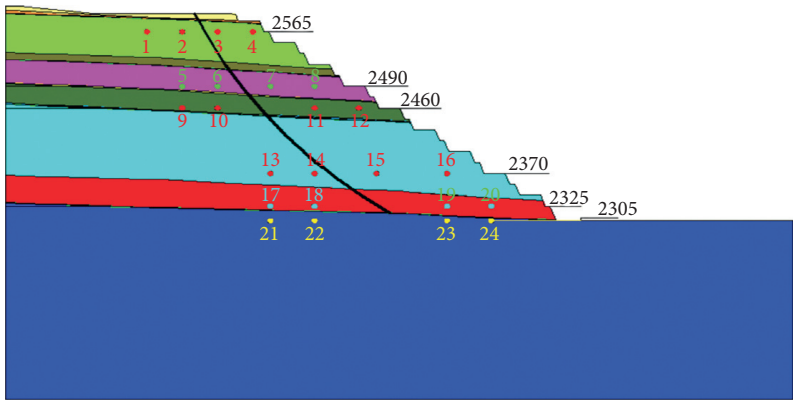

(e)

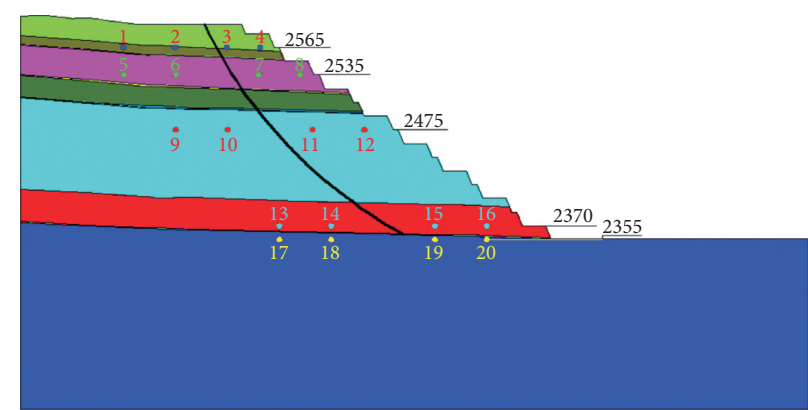

(d)

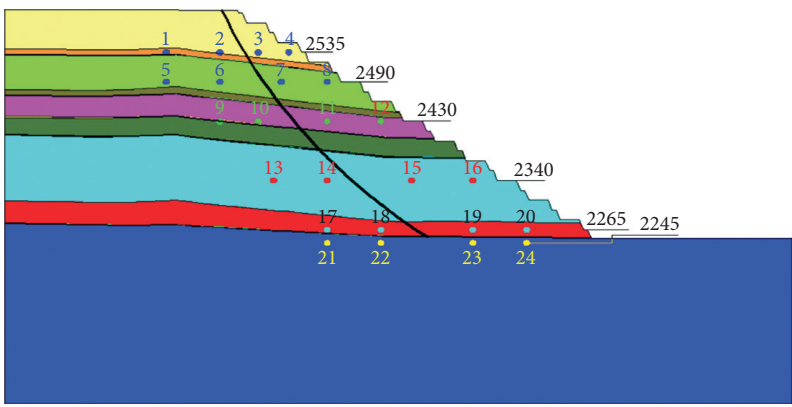

(f)

FIGURE 14: Monitoring point distribution map of profiles I-VI. (a) Distribution diagram of monitoring points in profile I. (b) Distribution diagram of monitoring points in profile II. (c) Distribution map of monitoring points in profile III. (d) Distribution map of monitoring points in profile IV. (e) Profile V monitoring point distribution map. (f) Profile VI monitoring point distribution map.
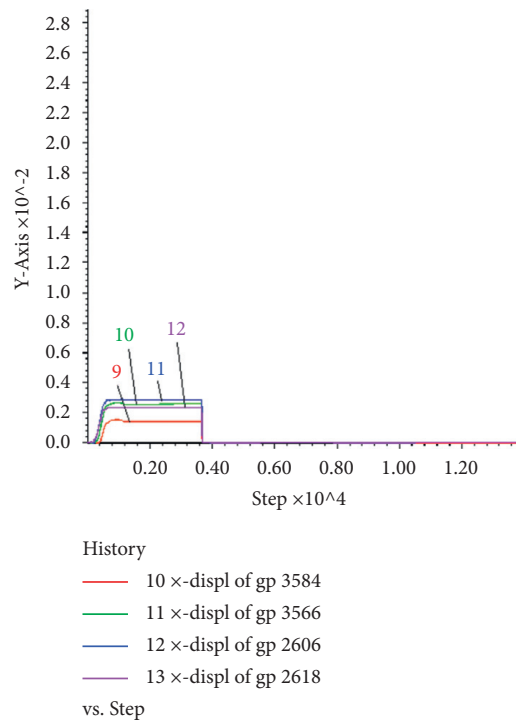

(a)

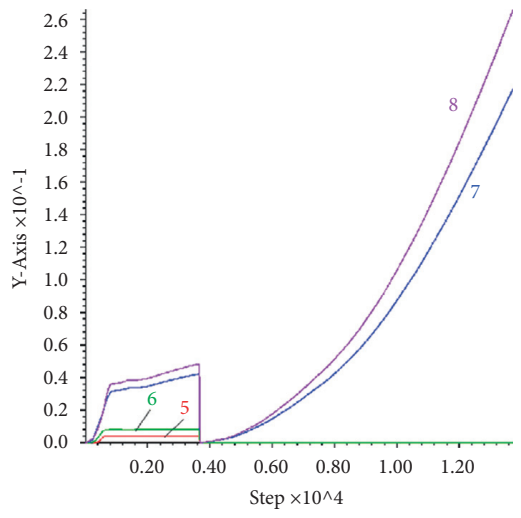

$$
\begin{aligned}
& \text { History } \\
& \begin{array}{l}
\text { 6x-displ of gp } 4088 \\
-\quad 7 \text {-displ of gp } 3899 \\
-\quad 8 \times \text {-displ of gp } 3689 \\
-\quad 9 \text {-displ of gp } 4310
\end{array} \\
& \text { vs. Step }
\end{aligned}
$$

(b)

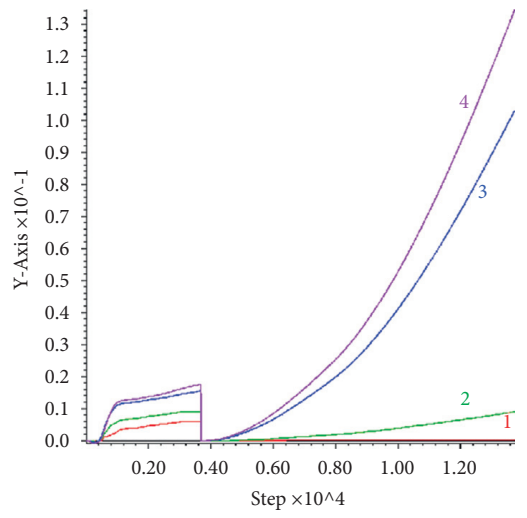

History

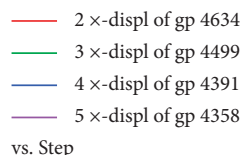

(c)

FIGURE 15: Horizontal displacement curve of profile I monitoring point. (a) 2580 level monitoring point, (b) 2520 level monitoring point, and (c) 2510 level monitoring point.

and it is gradually connected with the shear strain increment region at the bottom of the slope until it is through, forming an arc-shaped sliding failure surface. Finally, the slope sliding body is cut out from the foot of the slope, which is nearly consistent with the sliding surface of the limit equilibrium analysis results.
Figure 13 shows the plasticity differentiation layout. In the area showing the elastoplastic failure of the slope, the floor of the coal seam and the back part of the slope did not suffer any failure, while the rest area was in the yielding state (shear-n and determin-n). The yielding state area produced plastic flow and then produced failure, mainly shear failure. 


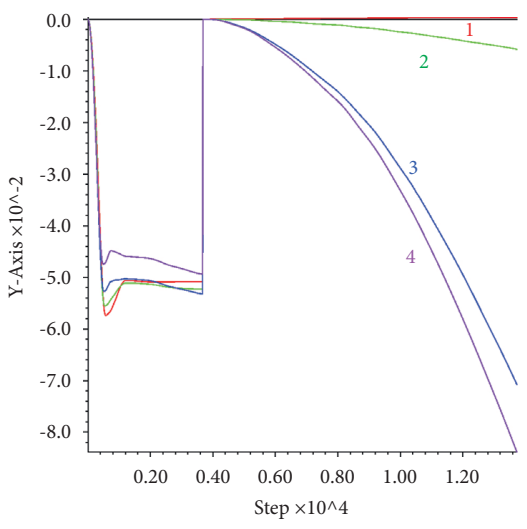

(a)

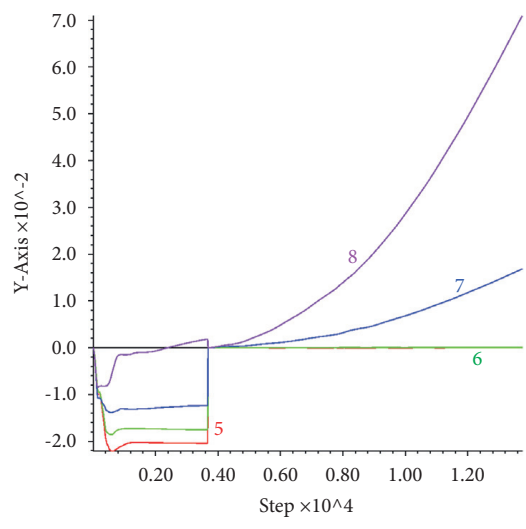

(b)

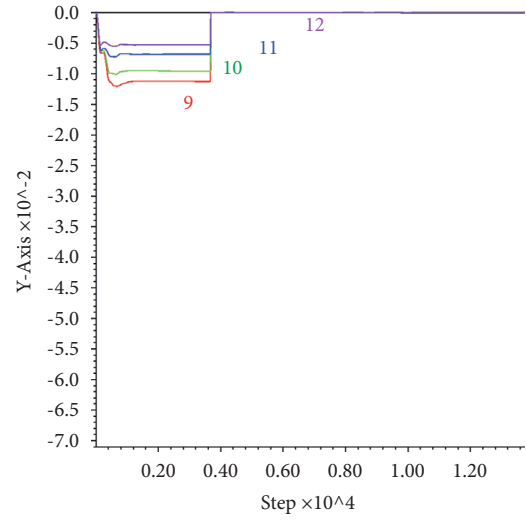

(c)

Figure 16: Monitoring points' Z-displacement of profile I: (a) 2580 level monitoring point, (b) 2520 level monitoring point, and (c) 2510 level monitoring point.

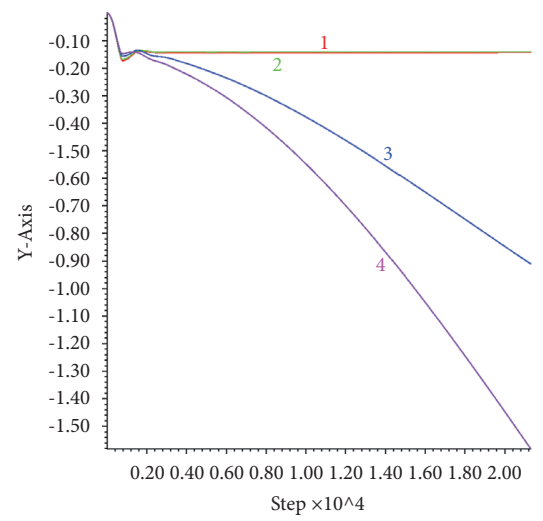

(a)

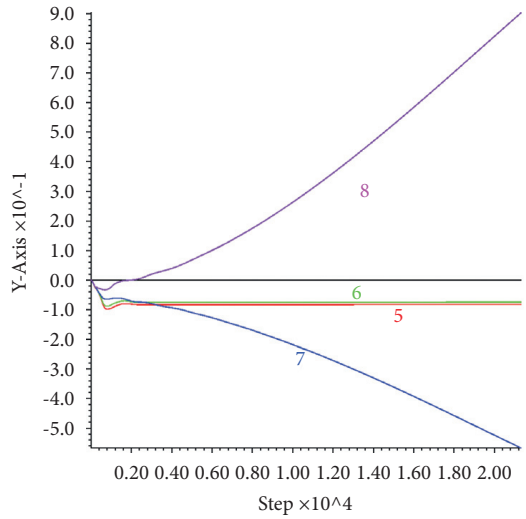

(b)

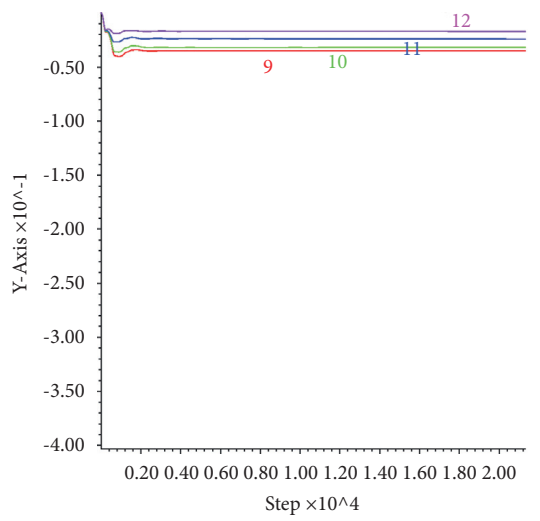

(c)

FIGURE 17: Monitoring points' Z-displacement of profile II: (a) 2565 level monitoring point, (b) 2475 level monitoring point, and (c) 2450 level monitoring point.

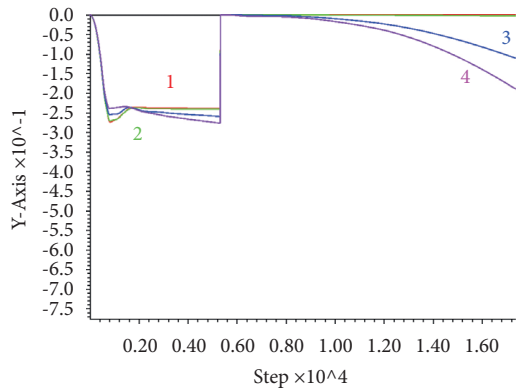

(a)

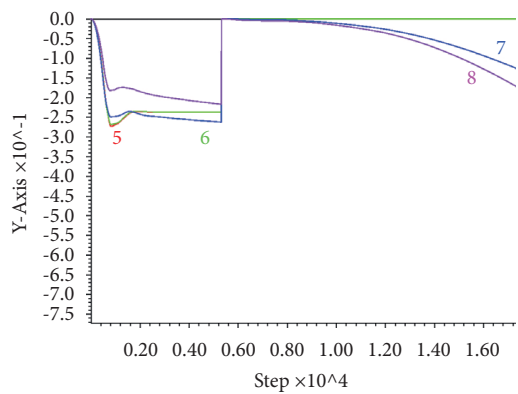

(b)

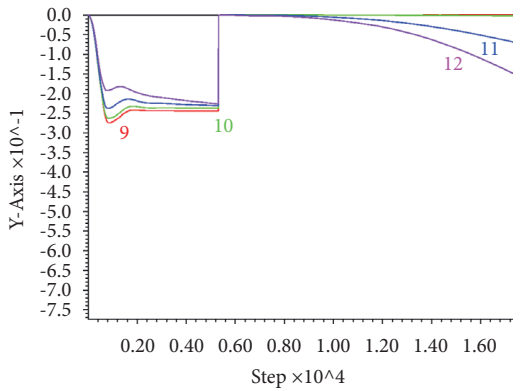

(c)

FIgURE 18: Continued. 


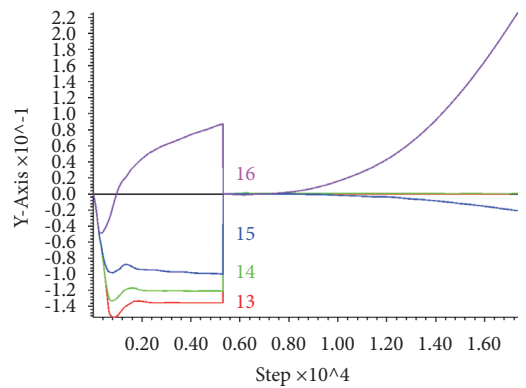

(d)

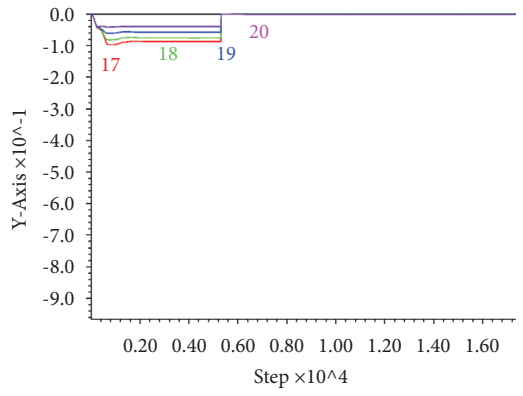

(e)

FIGURE 18: Monitoring points' Z-displacement of profile III: (a) 2565 level monitoring point, (b) 2545 level monitoring point, (c) 2490 level monitoring point, (d) 2415 level monitoring point, and (e) 2395 level monitoring point.

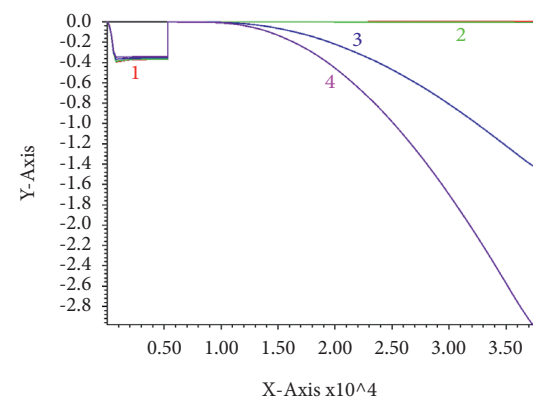

(a)

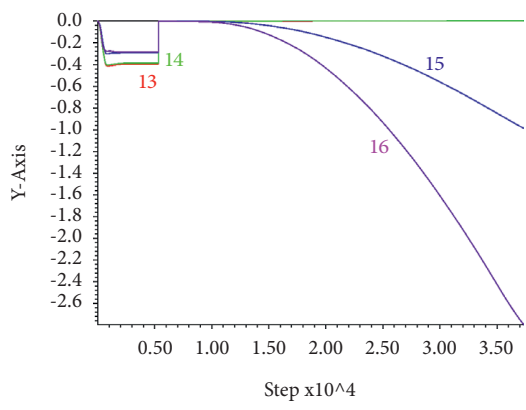

(d)

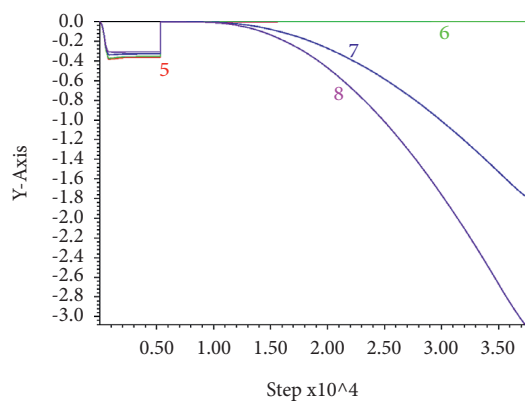

(b)

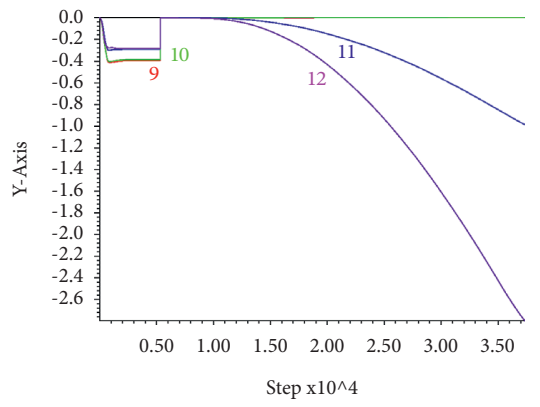

(c)

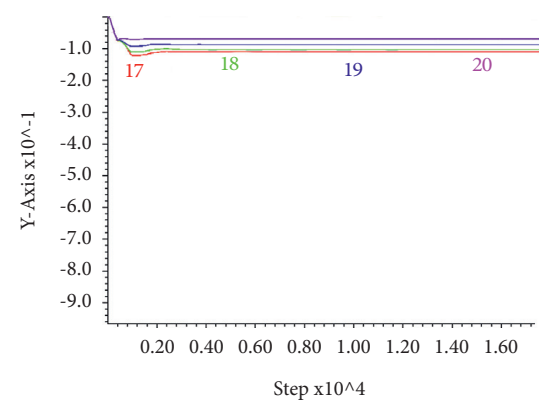

(e)

FIGURE 19: Monitoring points' Z-displacement of profile IV: (a) 2565 level monitoring point, (b) 2535 level monitoring point, (c) 2475 level monitoring point, (d) 2370 level monitoring point, and (e) 2355 level monitoring point.

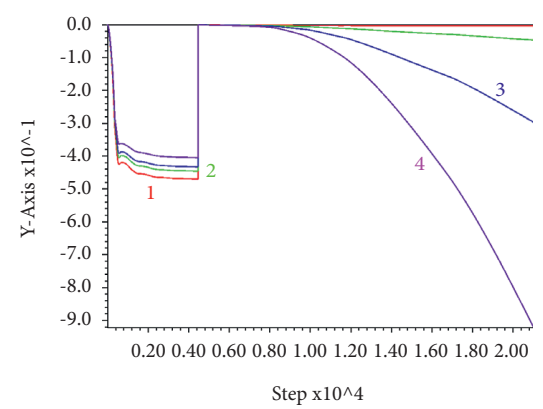

(a)

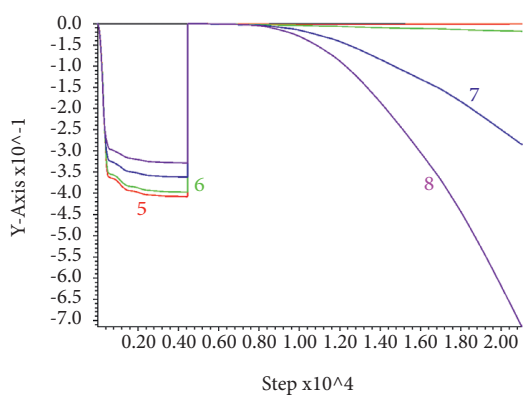

(b)

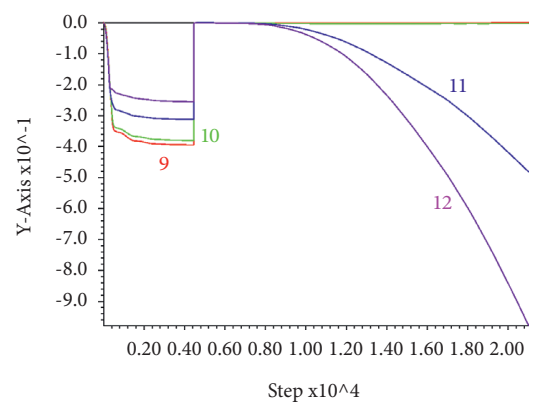

(c)

Figure 20: Continued. 


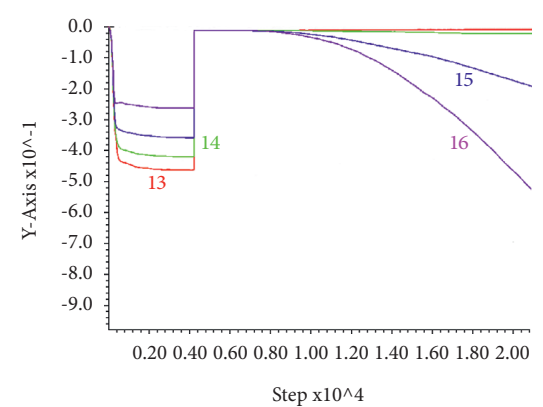

(d)

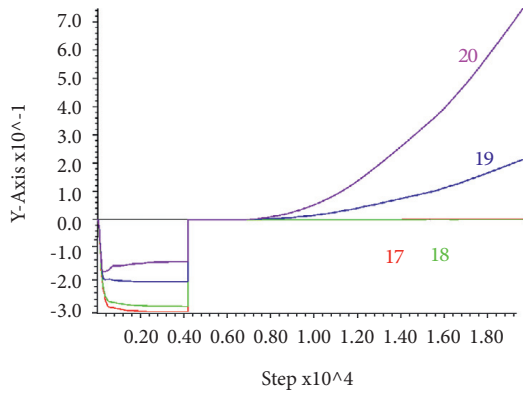

(e)

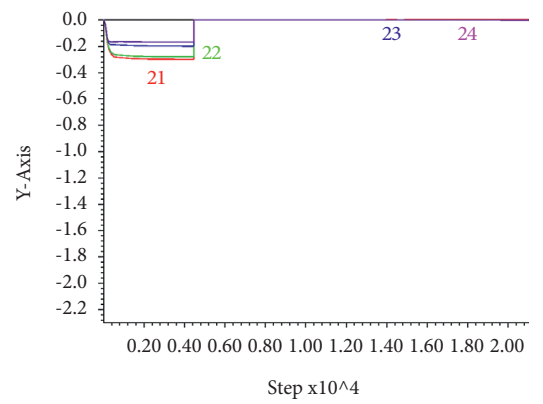

(f)

Figure 20: Monitoring points' Z-displacement of profile V: (a) 2565 level monitoring point, (b) 2490 level monitoring point, (c) 2460 level monitoring point, (d) 2370 level monitoring point, (e) 2325 level monitoring point, and (f) 2305 level monitoring point.

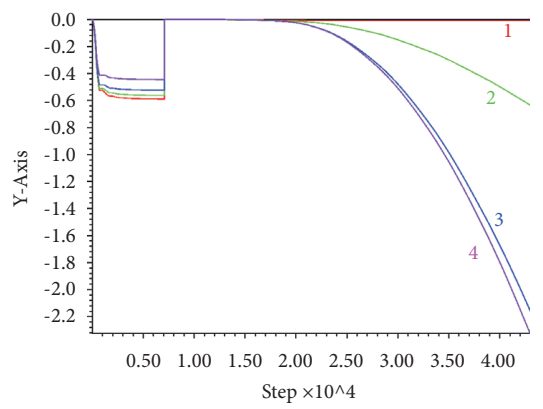

(a)

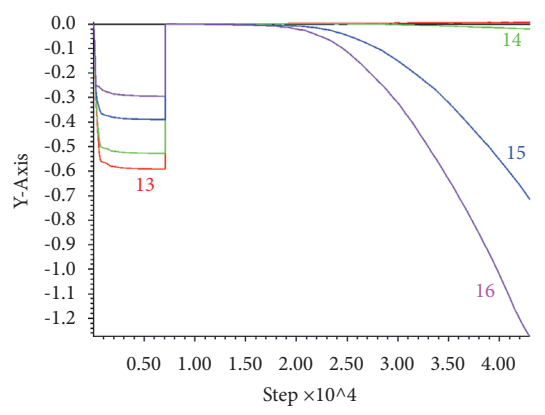

(d)

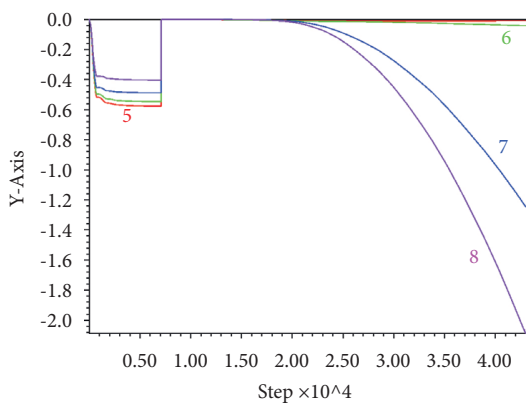

(b)

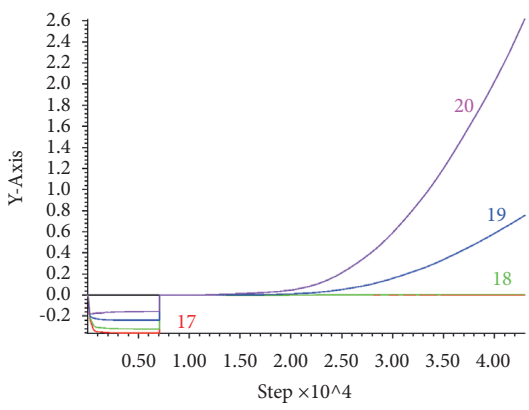

(e)

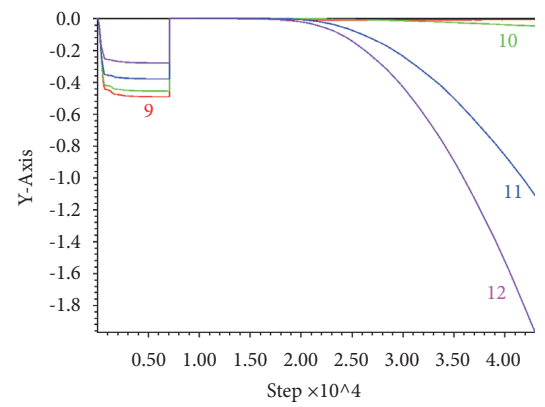

(c)

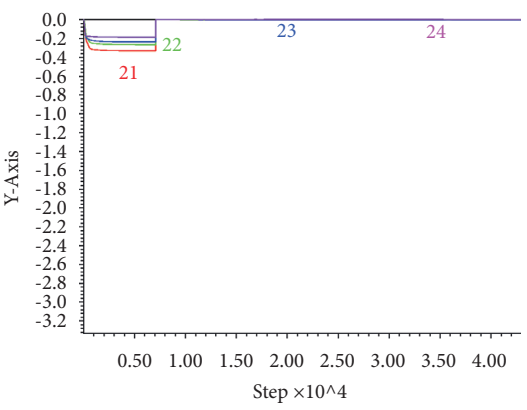

(f)

Figure 21: Monitoring points' Z-displacement of profile VI: (a) 2535 level monitoring point, (b) 2490 level monitoring point, (c) 2430 level monitoring point, (d) 2340 level monitoring point, (e) 2265 level monitoring point, and (f) 2245 level monitoring point.

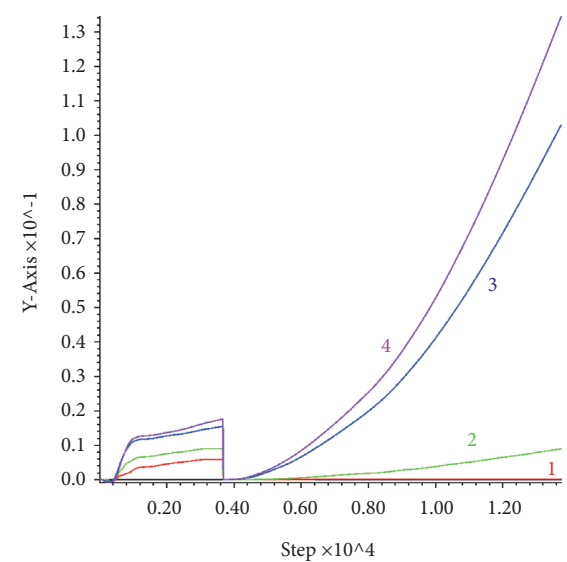

(a)

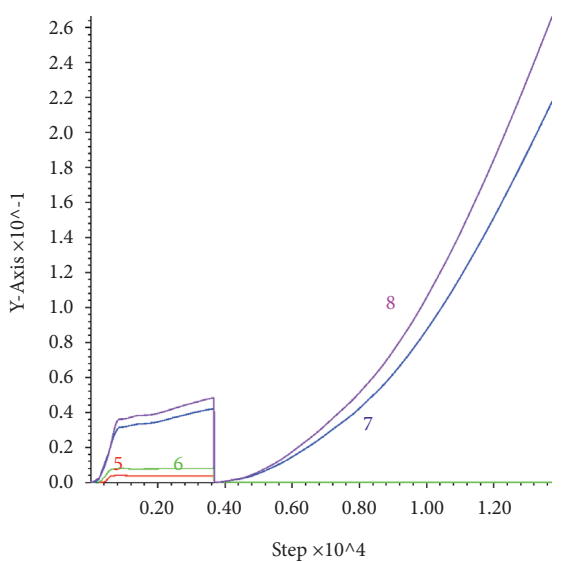

(b)

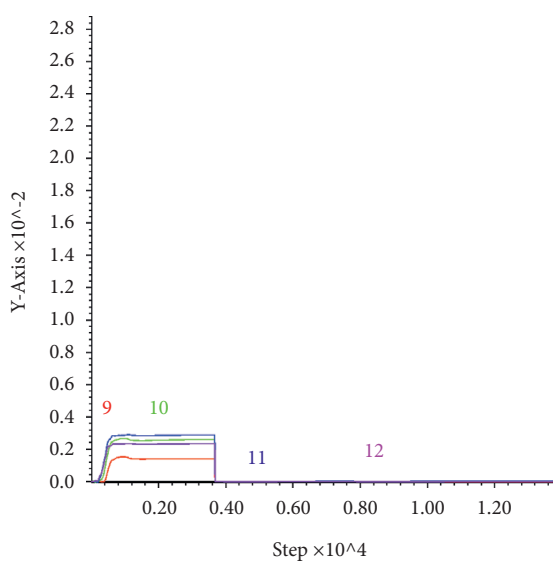

(c)

Figure 22: Monitoring points' X-displacement of profile I: (a) 2580 level monitoring point, (b) 2520 level monitoring point, and (c) level monitoring point. 


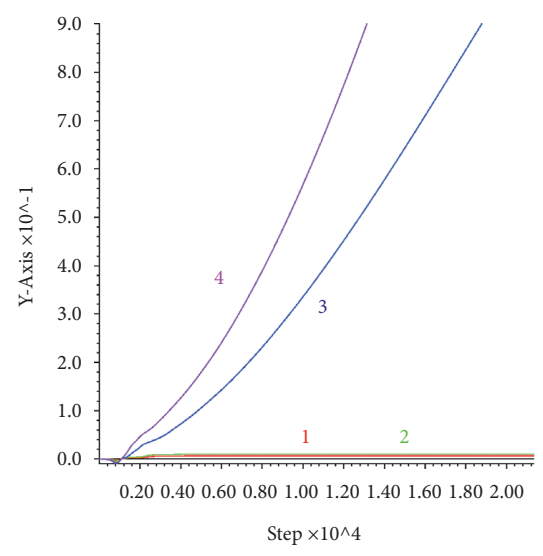

(a)

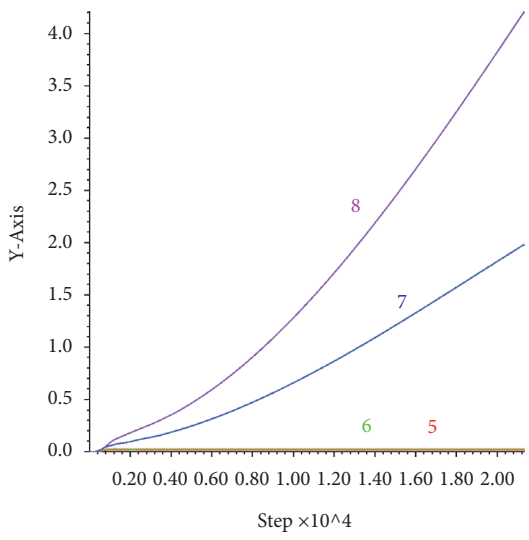

(b)

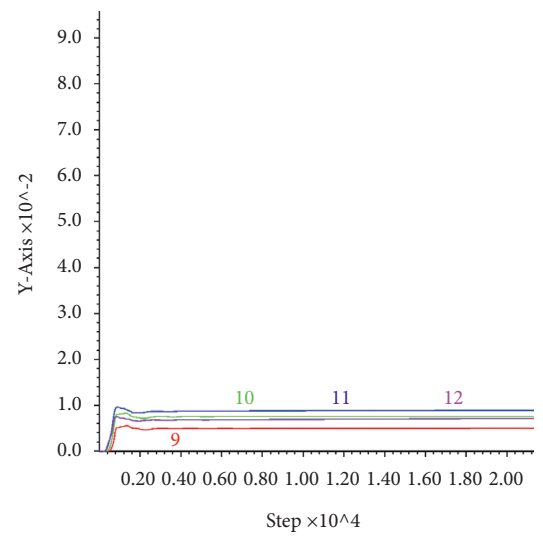

(c)

FIgURe 23: Monitoring points' X-displacement of profile II: (a) 2565 level monitoring point, (b) 2475 level monitoring point, and (c) 2450 level monitoring point.

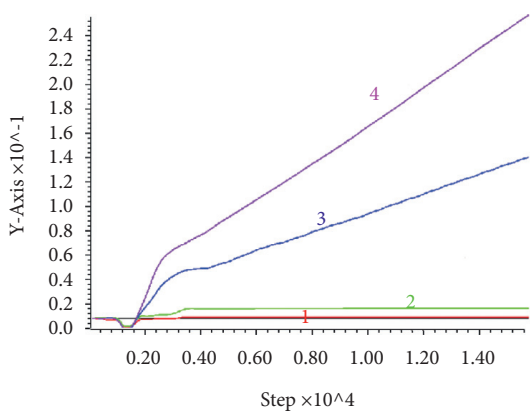

(a)

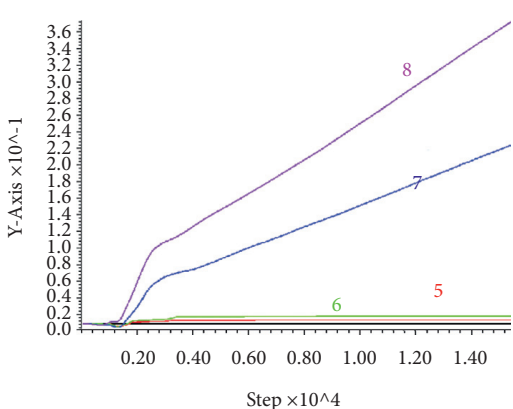

(b)

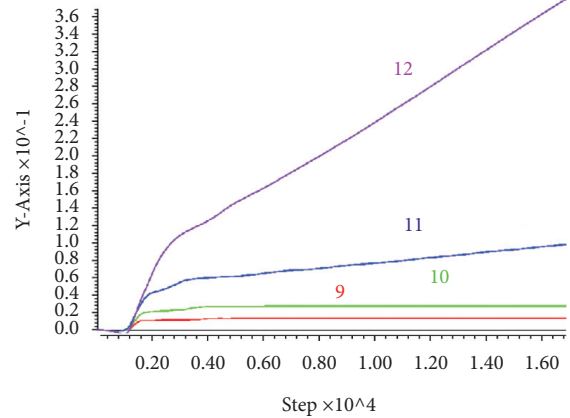

(c)

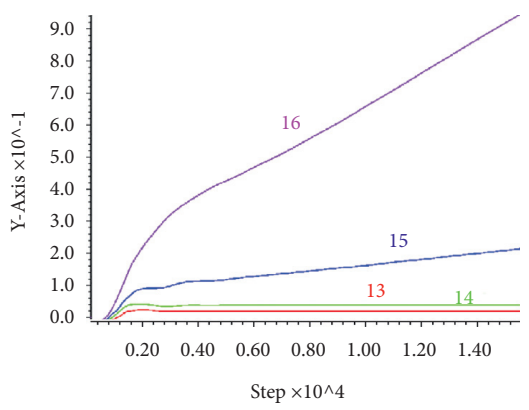

(d)

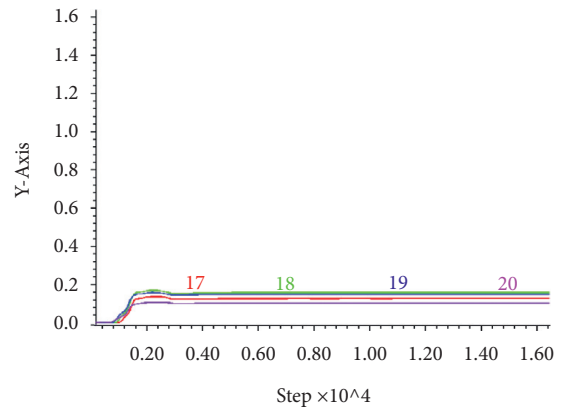

(e)

Figure 24: Monitoring points' X-displacement of profile III: (a) 2565 level monitoring point, (b) 2545 level monitoring point, (c) 2490 level monitoring point, (d) 2415 level monitoring point, and (e) 2395 level monitoring point.

The slope body is damaged along the internal shear plane, and the slide body is shearing and sliding along the weak layer (13-2 weak layer of coal floor).

4.3. Evolution Law of Displacement at the West End. In order to further reveal the evolution law of landslide displacement on the west end of the first mining area of Heishan open-pit mine, monitoring points are typically arranged on profiles
I-VI. The monitoring points are arranged in the landslide area, nonlandslide area, and coal seam floor of the slope, as shown in Figure 14. The distribution map of monitoring points on each profile is shown. Taking profile I as an example, there are 12 monitoring points in the model layout of profile I, and the monitoring points are located at the level of 2580, 2520, and 2510.

Figure 15 shows the horizontal displacement curve of the monitoring point in section I. The displacement of the 


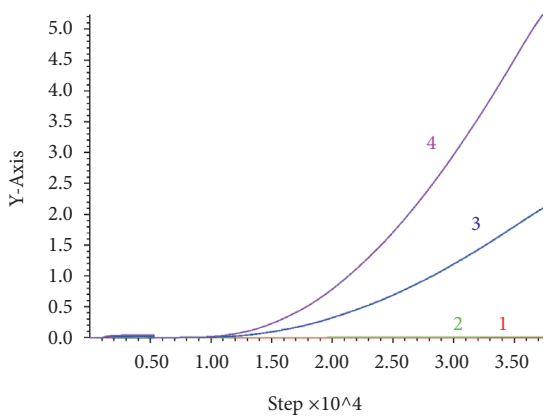

(a)

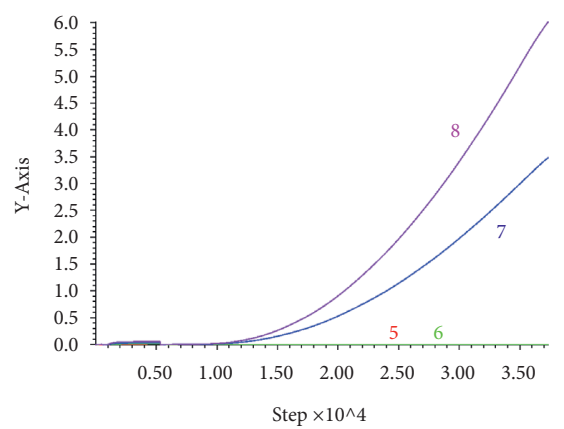

(b)

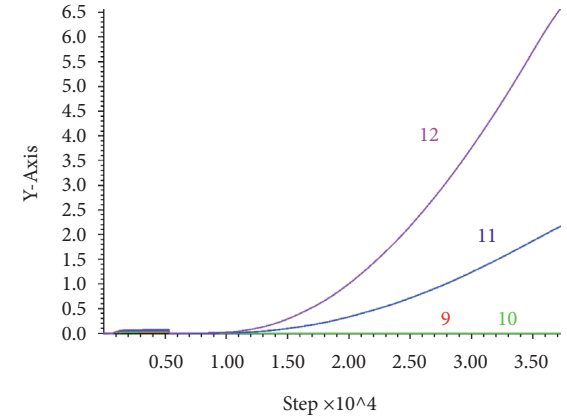

(c)

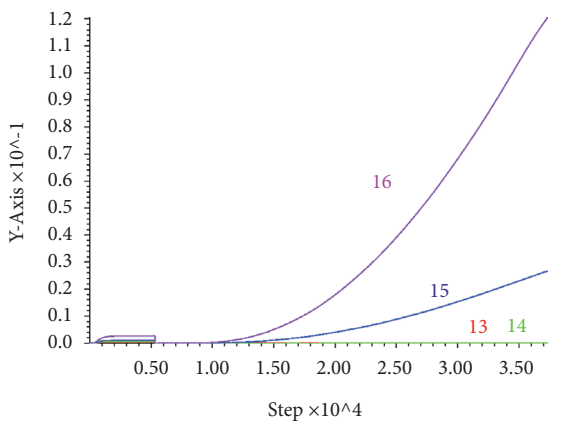

(d)

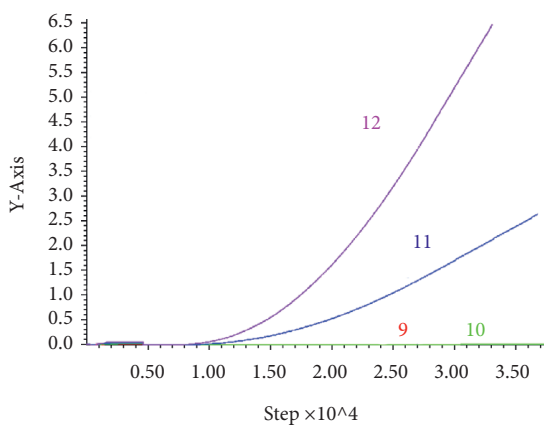

(e)

FIGURE 25: Monitoring points' X-displacement of profile IV: (a) 2565 level monitoring point, (b) 2535 level monitoring point, (c) 2475 level monitoring point, (d) 2370 level monitoring point, and (e) 2355 level monitoring point.

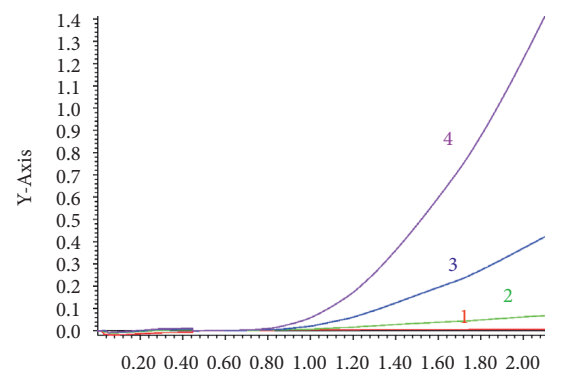

$\begin{array}{llllllllll}0.20 & 0.40 & 0.60 & 0.80 & 1.00 & 1.20 & 1.40 & 1.60 & 1.80 & 2.00\end{array}$ Step $\times 10^{\wedge} 4$

(a)

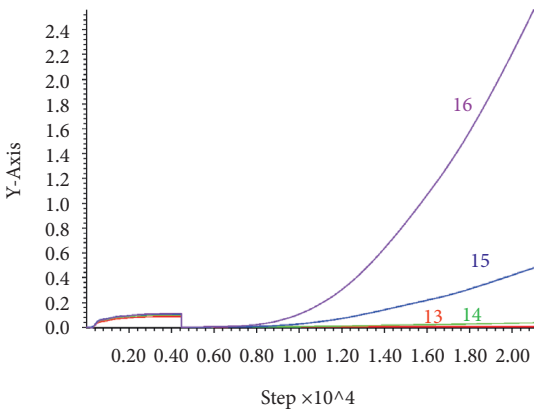

(d)

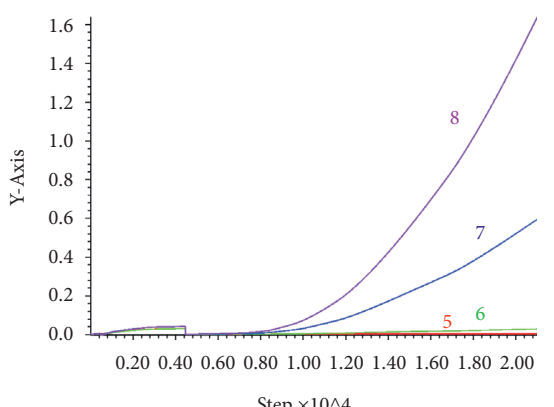

(b)

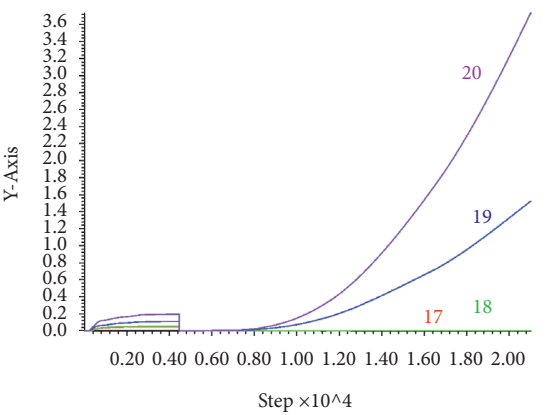

(e)

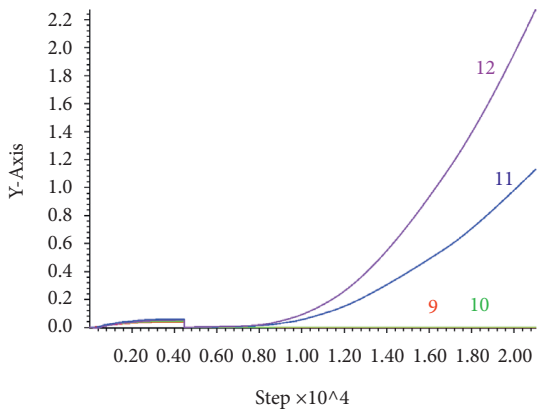

(c)

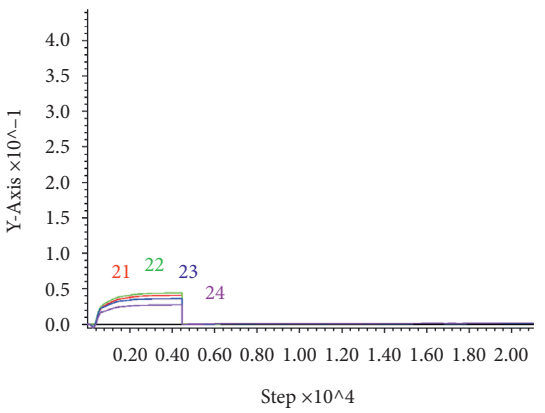

(f)

Figure 26: Monitoring points' X-displacement of profile V: (a) 2565 level monitoring point, (b) 2490 level monitoring point, (c) 2460 level monitoring point, (d) 2370 level monitoring point, (e) 2325 level monitoring point, and (f) 2305 level monitoring point. 


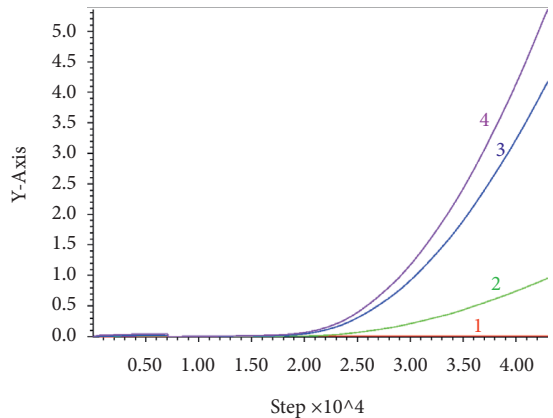

(a)

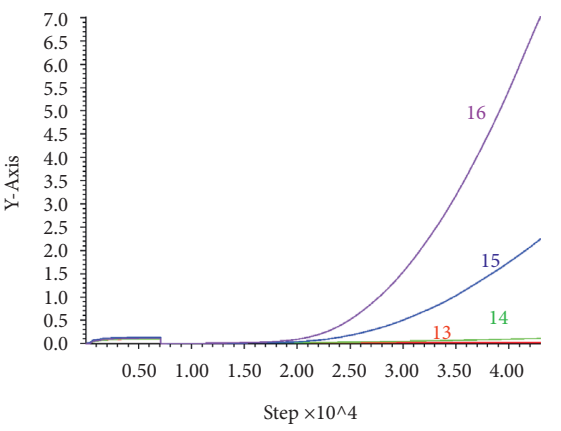

(d)

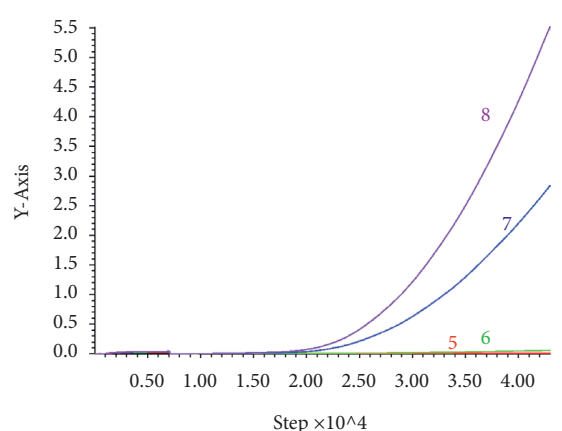

(b)

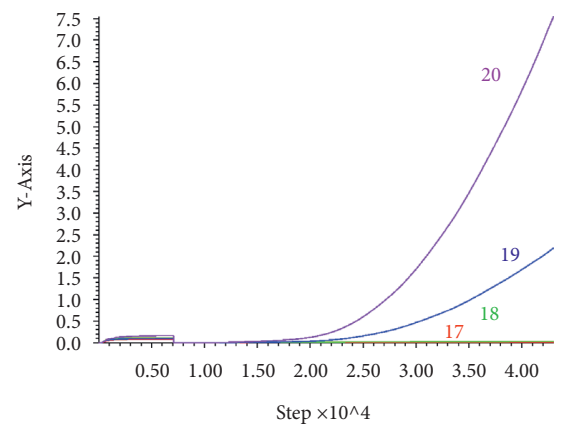

(e)

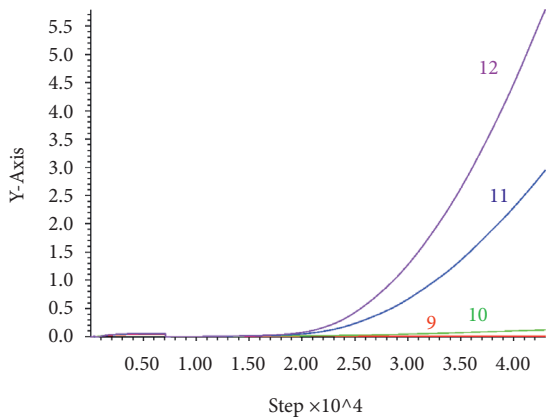

(c)

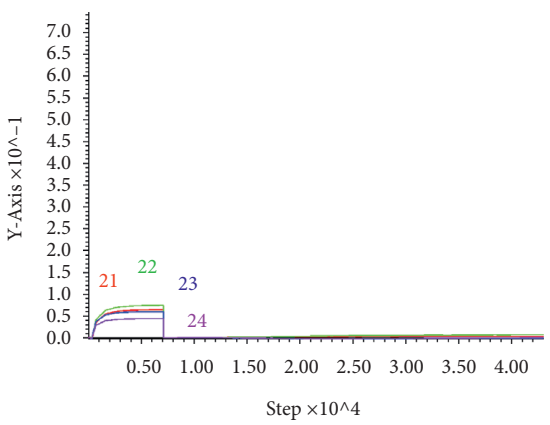

(f)

FIgURe 27: Monitoring points' X-displacement of profile VI: (a) 2535 level monitoring point, (b) 2490 level monitoring point, (c) 2430 level monitoring point, (d) 2340 level monitoring point, (e) 2265 level monitoring point, and (f) 2245 level monitoring point.

monitoring points in the nonlandslide area $(1,2,5,6)$ and the coal seam floor $(9,10,11,12)$ is small and then tends to be stable, while the displacement of the monitoring points in the landslide area $(3,4,7,8)$ increases significantly. The horizontal displacement of 2520 level monitoring point $(5,6$, $7,8)$ is the largest, and the closer it is to the slope surface, the larger the displacement is, indicating that the displacement of the weak layer along the 13-2 coal floor is the most obvious. The displacement of the 2510 level monitoring point $(9,10,11,12)$ of the coal floor is minimal and stable, indicating that the coal floor has not been damaged.

Figure 16 shows the vertical displacement curve of the monitoring point in profile I. The overall trend is roughly the same as the horizontal displacement curve. Compared with the horizontal displacement curve, the vertical displacement of the slope is very small, which indicates that the slope instability mainly occurs in the horizontal displacement.

According to the motion laws of the monitoring points in profiles I-VI of the figure, the monitoring points in each profile are bound by the sliding surface, and the motion laws are significantly different. The dislocations of the monitoring points in the nonlandslide area and the coal seam floor are small in the initial stage and then tend to be stable, while the dislocations of the monitoring points in the landslide area increase significantly. As the monitoring position gets closer to the slope, the displacement is greater, indicating that the displacement of the weak layer along the 13-2 coal floor is the most obvious. The displacement of the monitoring point of the coal floor is minimal and stable, indicating that no damage has occurred to the coal floor (Figures 17-27).

\section{Conclusion}

Based on the actual situation of the west end of the first mining area of Heishan open-pit coal mine in Xinjiang, this paper qualitatively analyzes the main factors affecting the slope and the potential landslide mode of the west end of the slope in combination with its geological characteristics. On this basis, the limit equilibrium analysis is carried out on the west end of the slope to judge the slope landslide mode and slope stability and to determine the final slope angle and morphological parameters of the west end. Finally, apply FLAC $^{3 \mathrm{D}}$ numerical simulation software to simulate the landslide mechanism and displacement evolution law of the west end wall. The conclusions are as follows:

(1) The main factors affecting the stability of the west slope are slope angle, slope height change, soft interlayer, etc. The landslide mode of the west-end slope is a combination of "cutting bed and bedding" sliding, and the weak bed of 13-2 coal floor plays a controlling role on the west-end slope. With the longitudinal mining depth, the slope height increases continuously, and the final slope angle decreases from $40^{\circ}$ to $37^{\circ}$, which determines the final slope shape of the west end.

(2) The main failure mode of the rock mass of the westend slope is shear failure. Under the action of gravity, the stress and strain concentration occurs at the weak layer and foot of the slope, and at the same time, the failure also occurs inside the slope body. Finally, the crack is through, and the weak layer of 13-2 coal floor is cut out at the foot of the side slope. 
(3) Analysis results of slope monitoring points show that the slope mainly has horizontal displacement, and the displacement near the slope surface is larger than that inside the slope, and the displacement at the foot of the slope is the largest.

(4) The research results can provide guidance for the production of open-pit mine and provide reference for slope stability analysis under similar conditions.

\section{Data Availability}

No data were used to support this study.

\section{Conflicts of Interest}

The authors declare that they have no conflicts of interest.

\section{Acknowledgments}

This research was supported by National Natural Science Foundation of China (Grant no. 51974144).

\section{References}

[1] H. Du, D. Song, Z. Chen, H. Shu, and Z. Guo, "Prediction model oriented for landslide displacement with step-like curve by applying ensemble empirical mode decomposition and the PSO-ELM method," Journal of Cleaner Production, vol. 270, p. 122248, 2020.

[2] M. Li, J. Zhao, J. Zhang, and S. Xiao, "Slope stability analysis based on leader dolphins herd algorithm and simplified Bishop method," IEEE Access, vol. 9, pp. 28251-28259, 2021.

[3] M. Li, X. Lai, J. Zhang, S. Xiao, L. Zhang, and Y. Tu, "Blastcasting mechanism and parameter optimization of a benched deep-hole in an opencast coal mine," Shock and Vibration, vol. 2020, Article ID 1396483, 11 pages, 2020.

[4] Z. Deng, X. Liu, Y. Liu et al., "Cumulative damage evolution and failure modes of the bedding rock slope under frequent microseisms," Arabian Journal of Geosciences, vol. 13, no. 10, 2020.

[5] Z. Song, T. Yang, and L. Zhao, "Comparative analysis of stability evaluation methods for diagenical rock slope with multi-layer weak interlayer," Chinese Journal of Geological Hazards and Prevention, vol. 27, no. 2, pp. 20-25, 2016.

[6] Z. Deng, X. Liu, Y. Liu et al., "Model test and numerical simulation on the dynamic stability of the bedding rock slope under frequent microseisms," Earthquake Engineering and Engineering Vibration, vol. 19, no. 4, pp. 919-935, 2020.

[7] Z. Wang, C. Han, D. Wang, Z. He, and B. Xu, "Analysis of failure process and its influencing factors of slope with soft interlayer," Safety in Coal Mines, vol. 48, no. 4, pp. 207-210, 2017.

[8] H. Peng, Q. Cai, W. Zhou, and J. Shu, "Research on key influencing factors of end-slope stability in sloping mining of open-pit coal mine," China Mining Industry, vol. 4, no. 5, pp. 71-74, 2008.

[9] W. Li, "Stability analysis of the north end slope of Haerwusu open-pit coal mine," Open Pit Mining Technology, vol. 4, no. 12, pp. 36-39, 2014.

[10] L. Cao, Z. Wang, D. Wang, and Z. Song, "Research on stability of end slope of reverse dip soft rock in open pit coal mine," Coal Science and Technology, vol. 45, no. 3, pp. 1-6, 2017.
[11] B. Xu, C. Yan, H. Chen, and W. Zhou, "Experimental study on mechanical properties of soft interlayer in slope rock mass," Rock and Soil Mechanics, vol. 4, no. 11, pp. 3077-3081, 2008.

[12] B. Xu, C. Yan, and S. Xu, "Analysis of the bedding landslide due to the presence of the weak intercalated layer in the limestone," Environmental Earth Sciences, vol. 70, no. 6, pp. 2817-2825, 2013.

[13] W. Cheng and W. Yu, "Influence of weak interlayer on slope stability of open pit mine," Inner Mongolia Coal Economy, vol. 4 , no. 2 , pp. $30-51,2016$.

[14] H. Basahel and H. Mitri, "Application of rock mass classification systems to rock slope stability assessment: a case study," Journal of Rock Mechanics and Geotechnical Engineering, vol. 9, no. 6, pp. 993-1009, 2017.

[15] S. Y. Liu, L. T. Shao, and H. J. Li, "Slope stability analysis using the limit equilibrium method and two finite element methods," Computers and Geotechnics, vol. 63, pp. 291-298, 2015.

[16] Y.-C. Yang, H.-G. Xing, X.-G. Yang, K.-X. Huang, and J.-W. Zhou, "Two-dimensional stability analysis of a soil slope using the finite element method and the limit equilibrium principle," The IES Journal Part A: Civil \& Structural Engineering, vol. 8, no. 4, pp. 251-264, 2015.

[17] F. R. Alam, K. Abbaszadeh, and A. Saied, "Strand current distribution modeling in turbo-generators using finite-element method based on proposed dual method," Electric Power Components and Systems, vol. 43, no. 2, pp. 134-145, 2015. 